\title{
Floor Plate and Netrin-1 Are Involved in the Migration and Survival of Inferior Olivary Neurons
}

\author{
Evelyne Bloch-Gallego, ${ }^{1}$ Frédéric Ezan, ${ }^{1}$ Marc Tessier-Lavigne, ${ }^{2}$ and Constantino Sotelo ${ }^{1}$ \\ 1/nstitut National de la Santé et de la Recherche Médicale U106, Hôpital de la Salpêtrière, 75013 Paris, France, and \\ 2Howard Hughes Medical Institute, Department of Anatomy, University of California at San Francisco, \\ San Francisco, California 94143
}

During their circumferential migration, the nuclei of inferior olivary neurons translocate within their axons until they reach the floor plate where they stop, although their axons have already crossed the midline to project to the contralateral cerebellum. Signals released by the floor plate, including netrin-1, have been implicated in promoting axonal growth and chemoattraction during axonal pathfinding in different midline crossing systems. In the present study, we report experiments that strongly suggest that the floor plate could also be involved in the migration of inferior olivary neurons. First, we show that the pattern of expression of netrin receptors DCC (for deleted in colorectal cancer), neogenin (a DCC-related protein), and members of the Unc5 family in wild-type mice is consistent with a possible role of netrins in directing the migration of precerebellar neurons from the rhombic lips. Second, we have studied mice deficient in netrin-1 production. In these mice, the number of inferior olivary neurons is remarkably decreased. Some of them are located ectopically along the migration stream, whereas the others are located medioventrally and form an atrophic inferior olivary complex: most subnuclei are missing.

Precerebellar neurons are known to follow circumferential migration routes. Thus, the pontine nuclei (Altman and Bayer, 1987b; Rakic, 1990), the external cuneatus nucleus (ECN), the lateral reticular nucleus (LRN), and the inferior olivary nucleus (ION) (Altman and Bayer, 1987a) all migrate from different regions of the alar ventricular zone of the rhombencephalon to their final destinations. The neurons of the ECN, LRN, and IO originate from the same neuroepithelium, and their proliferation time overlaps, although it occurs somewhat earlier for IO neurons than for ECN and LRN neurons: in the rat, IO neurons proliferate on embryonic day 12 (E12) and E13, whereas LRN and ECN neurons proliferate on E13 and E14 (Altman and Bayer, 1980, 1987a; Bourrat and Sotelo, 1988, 1991). Migration of IO neurons occurs through the submarginal stream (Altman and Bayer, 1980, 1987a; Bourrat and Sotelo, 1988, 1991), whereas other precerebellar neurons, LRN and ECN neurons, migrate

Received Jan. 15, 1999; revised March 8, 1999; accepted March 11, 1999.

This work was partially funded by European Commission Grant ERBBI04-CT960774 and Association pour la Recherche contre le Cancer Grant 9954. We are grateful to Frédéric Roger for technical assistance. We thank Drs. Patricia Gaspar, Pierre Angaut, and Nicole Dumesnil for critical reading of this manuscript, Charles Duyckaerts for assistance in cellular measurements, and Denis Le Cren for photographic work. We also thank Dr. D. S. Latchman for providing the Brn-3.b probe.

Correspondence should be addressed to Evelyne Bloch-Gallego, Institut National de la Santé et de la Recherche Médicale U106, Hôpital de la Salpêtrière, 75013 Paris, France.

Copyright @ 1999 Society for Neuroscience $0270-6474 / 99 / 194407-14 \$ 05.00 / 0$
However, axons of the remaining olivary cell bodies located in the vicinity of the floor plate still succeed in entering their target, the cerebellum, but they establish an ipsilateral projection instead of the normal contralateral projection. In vitro experiments involving ablations of the midline show a fusion of the two olivary masses normally located on either side of the ventral midline, suggesting that the floor plate may function as a specific stop signal for inferior olivary neurons. These results establish a requirement for netrin-1 in the migration of inferior olivary neurons and suggest that it may function as a specific guidance cue for the initial steps of the migration from the rhombic lips and then later in the development of the normal crossed projection of the inferior olivary neurons. They also establish a requirement for netrin-1, either directly or indirectly, for the survival of inferior olivary neurons.

Key words: development; neuronal migration; organotypic cultures; in situ hybridization; axonal tracing; carbocyanine; inferior olivary complex; floor plate; netrin-1; Unc-5H receptors; DCC receptor; survival through the marginal stream. More importantly, the cell bodies of LRN and ECN neurons cross the midline ventrally at the floor plate and continue their translocation until reaching their presumptive territories in the contralateral medulla oblongata. In contrast, olivary somata move up to the floor plate but stop before crossing the midline; each cell nucleus of the migrating IO neurons moves through its own leading process, which corresponds to the future axon, up to the floor plate, where it stops. The arrest of the migration of the soma occurs despite the fact that its axon has previously crossed the midline and reached the contralateral inferior cerebellar peduncle, its cerebellar entry. In rat, olivocerebellar axons reach the cerebellar plate at E16 and enter it at E17 (Wassef et al., 1992), a period coincident with the end of the IO migration, which lasts from E13 to E17. One of the striking characteristics of olivary neurons concerns the different behavior of somata and axons during their migration, in relation to the floor plate. These observations suggest that the floor plate contains or releases signals that affect olivary neurons differently from other precerebellar neurons. The responses to such signals must be different for the translocation of cell bodies and the guidance of olivary axons. The molecular cues that direct these developmental events remain unknown.

The guidance of growing neurites in the nervous system is, at least partly, mediated by diffusible chemoattractants (Ramon y Cajal, 1892; Kingsbury, 1920; Tessier-Lavigne et al., 1988) and/or 
chemorepellents (Pini, 1993) secreted by intermediate axonal target cells. In the spinal cord, the circumferential migrations of commissural axons are directed in part by chemoattractants of the netrin family (Kennedy et al., 1994; Serafini et al., 1994). In particular, netrin-1, which is expressed in the floor plate, has been shown directly to be required for growth of commissural axons to the floor plate (Serafini et al., 1996). In vertebrates, two families of receptors for netrin-1 have now been reported: members of the DCC (for deleted in colorectal cancer) family (DCC and neogenin; Keino-Masu et al., 1996) and the UNC5-H family (Ackerman et al., 1997; Leonardo et al., 1997). DCC is a netrin-binding protein expressed by the axons of commissural neurons as they project to the floor plate (Keino-Masu et al., 1996). Mice lacking DCC function (Fazeli et al., 1997) exhibit a phenotype relatively similar to that of mice carrying a severe hypomorphic allele of netrin-1 (Serafini et al., 1996), with, in each case, severe defects in the formation of the anterior commissure, absence of corpus callosum and pontine nuclei, reduction in size of the ventral spinal commissure, and errors in axonal pathfinding of commissural neurons in the spinal cord. Vertebrate homologs of Caenorhabditis elegans UNC5 are also netrin-binding proteins; these include the product of the mouse rostral cerebellar malformation gene RCM (renamed UNC5H3; Ackerman et al., 1997, Przyborski et al., 1998) and of two rat genes, UNC5H1 and UNC5H2 (Leonardo et al., 1997). By homology with the presumed function of C. elegans UNC5 as a repulsive netrin receptor (Culotti and Kolodkin, 1996), it is thought that they are responsible for signaling mechanisms through which netrins elicit repulsive responses. UNC5H1 and UNC5H2 are coexpressed with DCC in ventral and dorsal spinal cord, in the dorsal part of the retina, and in the cerebellum and sensory ganglia (Leonardo et al., 1997). UNC5 homologs have been proposed to interact with DCC to form a complex, transforming an attractive response to netrin-1 mediated by DCC into a repulsive function for the same molecule (Culotti and Kolodkin, 1996; Leonardo et al., 1997; Hong et al., 1998).

Our current research is aimed at understanding more specifically the role of the floor plate and netrin- 1 in the formation of the olivocerebellar projection, particularly in the migration of inferior olivary neurons. Previous studies had suggested possible roles for netrin-1 and its receptors in retinal, striatal, nigral, and cerebellar neuron development (Deiner et al., 1997; Livesey and Hunt, 1997), as well as in the guidance of corticothalamic axons (Métin et al., 1997; Richards et al., 1997). We report here experiments and results concerning the effects of the floor plate, netrin-1, and its receptors on migration and survival of precerebellar neurons and acquisition of their cytoarchitectonic adult organization and connections.

\section{MATERIALS AND METHODS}

\section{Fixation}

Mouse embryos were obtained from timed mating of outbred OF1 mice (IFFA Credo, Lyon, France). Chick embryos (JA57) were purchased from Morizeau, and their developmental stage was determined at the moment of fixation according to Hamburger and Hamilton (1951). For in situ hybridization (ISH), the embryos were fixed in $2 \%$ parafomaldehyde (PF), $4 \%$ sucrose, and $0.12 \mathrm{~mm} \mathrm{CaCl}_{2}$ in phosphate buffer, $\mathrm{pH} 7.4$. The neural tubes were dissected out, embedded in $1.5 \%$ agar and $5 \%$ sucrose, and cryoprotected overnight with $10 \%$ sucrose solution (in phosphate buffer, $\mathrm{pH}$ 7.4). When used for immunocytochemistry, embryonic mice and chicks and newborn mice were fixed with $4 \% \mathrm{PF}$, embedded in $7.5 \%$ gelatin and $10 \%$ sucrose, and cryoprotected as described above. Mouse embryos from E11 to E14 were fixed by immersion, whereas from E14, they were perfused through the heart with the appropriate fixative and post-fixed overnight at $4^{\circ} \mathrm{C}$ in it. Chick embryos up to stage 30 of Hamburger and Hamilton (HH30) were fixed by immersion and perfused when older as described above for mice. Then they were frozen in isopentane cooled to $-55^{\circ} \mathrm{C}$ with liquid nitrogen.

The frozen brains were serially sectioned in a cryostat in the frontal or sagittal planes. The sections ( $20 \mu \mathrm{m}$ thick) were mounted on four parallel sets of slides.

\section{In situ hybridizations and combined immunocytochemistry}

The chick netrin-1 subclone (Serafini et al., 1994) was linearized with EcoRI or XhoI (Pharmacia, Uppsala, Sweden) and transcribed in the presence of digoxigenin (Dig)-UTP (Boehringer Mannheim, Mannheim, Germany) using T7 RNA polymerase or T3 RNA polymerase (riboprobe kit; Promega, Madison, WI) to produce the antisense or sense probes, respectively. The mouse netrin subclone (Serafini et al., 1996) was linearized with EcoRI or $S a c$ I and transcribed in the presence of Dig-UTP using T3 RNA polymerase or T7 RNA polymerase to produce the antisense or sense probes, respectively. No signal was obtained when using the sense probes. The mouse DCC (Keino-Masu et al., 1996) subclone called $D 78$ was linearized with $A p a \mathrm{I}$ or $K p n \mathrm{I}$ and transcribed in the presence of Dig-UTP using SP6 or T7 RNA polymerase to produce the antisense or sense probes, respectively. The rat Unc-5H1 probe (Leonardo et al., 1997) was linearized with $\mathrm{XbaI}$ or $\mathrm{KpnI}$ and transcribed in the presence of DigUTP using or T3 polymerase to produce the antisense or sense probes, respectively. The rat Unc-5H2 probe (Leonardo et al., 1997) was linearized with NotI or HincII and transcribed in the presence of Dig-UTP using T7 or T3 RNA polymerase to produce the antisense or sense probes. The mouse Unc-5H3 probe (Leonardo et al., 1997) was linearized with BamHI or KpnI and transcribed in the presence of dig-UTP using T7 or T3 RNA polymerase to produce respectively the antisense and sense probes. The rat neogenin probe, called N78 (Keino-Masu et al., 1996), was linearized with XbaI and transcribed in the presence of Dig-UTP using sp6 RNA polymerase to produce the antisense probe. The mouse Brn-3.b probe (Wyatt et al., 1998) was linearized with NotI and NcoI and transcribed in the presence of Dig-UTP using T7 or sp6 RNA polymerase to produce respectively the antisense or sense probes. ISH was performed according to Myat et al. (1996). The probe was revealed using an anti-digoxigenin-alkaline phosphatase Fab antibody (1:2000; Boehringer Mannheim) and nitroblue tetrazolium 6-bromo-4-chloro-3-indolyl phosphate (NBT-BCIP) (Boehringer Mannheim) as a substrate for the alkaline phosphatase.

In some experiments, the ISH was then combined with immunohistochemistry with an anti-calbindin $(\mathrm{CaBP})$ antibody, which resists the ISH protocol. The polyclonal anti-CaBP antibody $(1: 15,000$; Swant) was incubated overnight and revealed with an anti-rabbit biotinylated antibody (1:200; Vector Laboratories, Burlingame, CA) and a streptavidin-Texas Red antibody (1:150; Amersham, Arlington Heights, IL).

\section{Antibodies used for immunocytochemistry of newborn normal and netrin-1 mutant mice}

Both wild-type and mutant for netrin- 1 expression newborn mice were fixed by perfusion with $4 \%$ PF and cryoprotected in $30 \%$ sucrose. Four serial alternated frozen coronal sections, $30 \mu \mathrm{m}$ thick, were collected and processed free-floating using two antibodies in combination: anti-CaBP and anti-calcitonin gene-related peptide (CGRP). The polyclonal antiCGRP antibody (1:5000; Peninsula Laboratories, Belmont, CA) was incubated overnight at room temperature on a rotatory shaker with the primary antibody, which was subsequently revealed with diaminobenzidine (DAB) according to the amplification protocol using a secondary biotinylated antibody (1:200; Vector) and then recognized with a peroxidase complex coupled to streptavidin (Amersham). Then the polyclonal anti-CaBP antibody (1:15,000; Swant) was incubated overnight as described above and revealed with an anti-rabbit biotinylated antibody (1:200; Vector) and a streptavidin-Texas Red antibody (1:150; Amersham).

\section{DiI tracing: retrograde labeling of precerebellar neurons}

After intracardiac perfusion with $1 \% \mathrm{PF}$ and $1 \%$ glutaraldehyde in 0.12 M phosphate buffer, $\mathrm{pH} 7.4$, a small occipital craniotomy was performed to expose the cerebellum of newborn [postnatal day 0 (P0)] wild-type or netrin-1 hypomorphic mutant mice. 1,1'-Dioctadecyl-3,3,3',3'tetramethylindocarbocyanine (DiI carbocyanine, D282; Molecular Probes, Eugene, OR) attached to the tip of a broken glass pipette was applied, under a dissecting microscope, on one of both hemicerebella. 
Several small DiI crystals were inserted into the cerebellar tissue, medially and laterally to label most of the neurons projecting to this center. The brains of the injected mice, still protected in their bony envelopes, were stored in $1 \% \mathrm{PF}$ at $37^{\circ} \mathrm{C}$ for 3 weeks in the dark. The brains were then dissected, embedded in 3\% agarose, and cut at a thickness of $80 \mu \mathrm{m}$ with a vibratome. The sections were mounted in Mowiol, observed, and photographed by using rhodamine filters.

\section{Volumetric and cellular densitometric measurements}

Quantification of both IO ectopia and medio-ventral ION on cryostat sections after ISH. Newborn mice were fixed by a perfusion throughout the heart using $4 \% \mathrm{PF}$. The medulla oblongata was dissected in the same fixative and processed for ISH using Brn-3.b antisense probe on $20-\mu \mathrm{m}$ thick cryostat sections. Brn-3.b-positive neurons were counted using the following procedure. In each animal, only the left or right ION was studied. One of every four sections was examined in both normal and mutant mice. In mutant cases, we considered as olivary cells Brn-3.bpositive neurons located both medioventrally close to the floor plate and more dorsolaterally along or in the vicinity of the submarginal stream.

Quantification of ventromedially located ION on paraffin sections. Newborn mice were fixed as described above. Dissected medulla oblongata were post-fixed for $4 \mathrm{hr}$ in Carnoy fixative, dehydrated, and embedded in paraffin. For each animal, 7.5- $\mu \mathrm{m}$-thick serial paraffin sections through the ION were cut and stained with cresyl violet. The neurons were counted using the following procedure. In each animal, only the left or right ION was studied. From olivary sections obtained from newborn mice, 1 of every 24 and 1 of every 12 sections was examined for normal and mutant mice, respectively. In mutant cases, we considered as olivary cells neurons located close to the floor plate that appeared as small clusters of elongated cells, with a medioventral location.

Whatever the material, paraffin sections stained by the Nissl method or cryostat sections after ISH, the volumetric measurements were performed using the technique of "point counting" at a magnification of $10 \times$ for paraffin sections and $5 \times$ for cryostat sections, and the densitometric measurements were performed by the disector method (Coggeshall and Lekan, 1996) at a $100 \times$ magnification. The results in each case, normal and mutant, were grouped, and SDs were calculated.

\section{Organotypic cultures}

Fertilized JA57 hens' eggs obtained from local farms were incubated at $38^{\circ} \mathrm{C}$ in a humidified atmosphere. After $5.5 \mathrm{~d}$ of incubation (HH28HH29; Hamburger and Hamilton, 1951), embryos were collected, staged, and decapitated. The heads were put into ice-cold Gey's balanced salt solution with $5 \mathrm{mg} / \mathrm{ml}$ glucose (GBSS), and the brains were quickly dissected out and left in GBSS. The brain region posterior to the cerebellar anlage up to the caudal portion of the medulla oblongata, containing the inferior olive, was obtained. One hundred fifty to $200 \mu \mathrm{m}$ coronal slices were cut and transferred onto the membrane of a $30 \mathrm{~mm}$ Millipore culture insert plate (pore size, $0.4 \mu \mathrm{m}$; Millicell CM; Millipore, Bedford, MA; Stoppini et al., 1991) in $100 \mathrm{~mm}$ culture dishes containing $3 \mathrm{ml}$ of medium composed of 50\% Eagle's basal solution, 25\% HBSS, 5 $\mathrm{mg} / \mathrm{ml}$ glucose, $10 \mathrm{~mm}$ glutamine, and $25 \%$ horse serum, all purchased from Life Technologies (Gaithersburg, MD). The slices were positioned, and excess of GBSS was carefully removed with a Pasteur pipette. The Petri dishes were then placed in an atmosphere of humidified $5 \% \mathrm{CO}_{2}$. Cultures were fixed at different times in culture and processed for immunocytochemistry or ISH.

\section{Lesions of the floor plate}

The floor plate was mechanically lesioned on each slice positioned on the membrane. Using a thin needle, cell bodies of the floor plate were removed (see Fig. 9A), which led to a degeneration of their long processes. The quality of the lesion was controlled after fixation and immunohistochemistry with an anti-Ben antibody (see below), and the cases were classified according to the aspect of the remaining floor plate, which could be absent, lesioned, or intact.

\section{Immunohistochemical study of the slices}

After 1 to $4 \mathrm{~d}$ in culture, slices were fixed with $4 \% \mathrm{PF}$ in $0.12 \mathrm{M}$ phosphate buffer, $\mathrm{pH} 7.2-7.4$, for $1 \mathrm{hr}$ at room temperature. After fixation, the slices were washed with PBS and $0.05 \%$ Triton X-100, transferred to a 24-well dish, and processed for immunohistochemistry. Control and lesioned slices were immunostained with a monoclonal anti-Ben antibody (1: 20,000; Pourquié et al., 1990), which is a marker of inferior olivary neurons, to determine whether these neurons had survived in the culture conditions and succeeded to reach their position on each side of the midline. The antibody was incubated in PBS, $0.2 \%$ gelatin, and $0.25 \%$ Triton X-100 overnight and revealed using an FITC-conjugated antimouse antibody (1:50; Amersham).

\section{RESULTS}

\section{Netrin-1 and both of its receptors are expressed in the developing inferior olivary region}

We have studied the expression of netrin- 1 and the netrin receptor genes DCC, neogenin, Unc-5H1, Unc-5H2, and Unc-5H3 throughout the development of the inferior olive from E11 to P0, i.e., from the beginning of the phase of neuronal migration to the formation of the mature layered IO complex. IO cells are identifiable by their expression of Brn-3.b mRNA.

The time of birth of IO neurons, E10-E11, which was inferred from experiments using tritiated thymidine incorporation, lasts $\sim 48 \mathrm{hr}$ (data not shown). At E11-E12, thus coincident with the end of the proliferation and the onset of migration of IO neurons (Fig. 1A,B), expression of netrin-1 is very intense in the epithelial cells forming the floor plate (Fig. $1 C$ ) and gradually decreases in intensity within the neuroepithelium mediolaterally up to the sulcus limitans. Neogenin mRNA (Fig. 1D) is expressed along the whole ventricular zone, in a thin and deep periventricular band. In addition, two lines of expression underline the rhombic lips with exactly the same distribution as Unc-5H1 mRNA (data not shown). Unc-5H2 mRNA is expressed in the caudal rhombic lip, in a pattern complementary to that of netrin-1, because it is restricted in the ventricular neuroepithelium dorsal to the sulcus limitans but with no clear boundary between both domains (Fig. $1 E$ ). The expression domain of Unc-5H2 presents a thicker aspect, in the alar domain, compared with the one of $U n c-5 H 1$ and neogenin. DCC mRNA is expressed in all early postmitotic cells of the hindbrain (basal and alar), in a zone located immediatly deep to the ventricular zone, including those originating from the caudal rhombic lips (Fig. $1 F$ ) and ventral cells that will follow a radial migration. Thus, there appears to be no overlap in the expression domains of Unc-5H2 and DCC, whereas Unc-5H1, Unc-5H2, and neogenin colocalize in the alar part of the ventricular zone.

At E13, IO neurons begin to reach the vicinity of the floor plate, as observed in cresyl violet-stained preparations (Fig. $2 A$ ), and after ISH using Brn-3.b (Fig. $2 B$ ), numerous IO neurons were still migrating toward the olivary territory, whereas others were already packed in a club-shaped domain close to the floor plate. At this stage, axons of ventrally packed IO neurons have crossed the midline through the interolivary commissure and reached the inferior cerebellar peduncle; indeed, a unilateral DiI injection (schematized in Fig. 2C) into the cerebellum labels IO neurons in the club-shaped mass close to the bulbar midline, contralaterally to the injection site (Fig. 2D). At this stage (E13), high levels of netrin-1 are still expressed in the floor plate cells, with a similar graded and spreading pattern as at E12 (Fig. 2E). Unc-5H2 mRNA is detected in the caudal rhombic lip with the same pattern as at E12 (results not shown). Neither neogenin nor Unc-5H2 mRNAs are expressed in the club-shaped masses of IO neurons, whereas $D C C$ mRNA is now expressed by IO neurons located close to the midline (Fig. 2E).

At E15, when the IO axons start to penetrate into the cerebellar parenchyma, the ventral cellular masses constituting the IO territory are highly enlarged by accumulation of late generated 


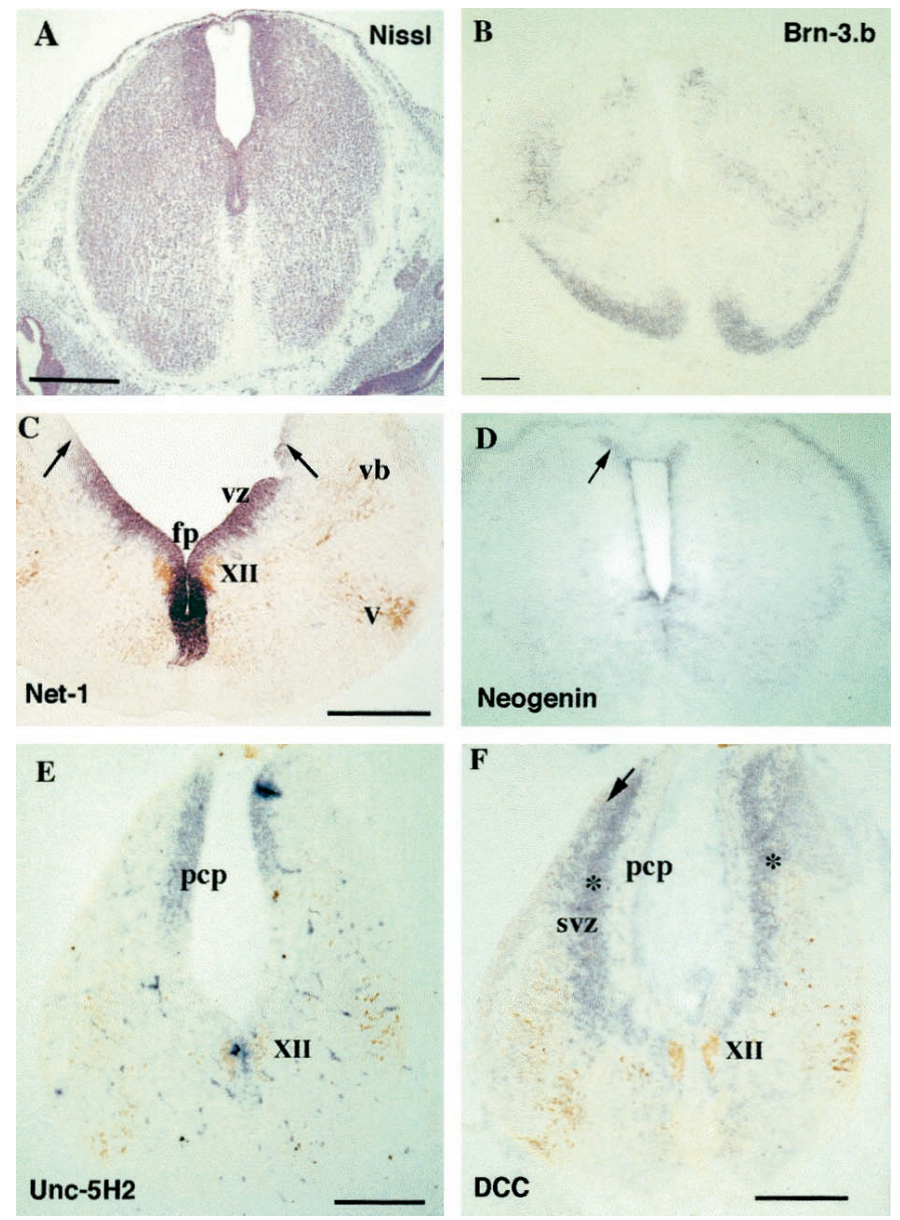

Figure 1. At embryonic day 12, expression of Brn-3.b, netrin-1, DCC, neogenin, and Unc-5H2 in wild-type mouse. A, Nissl stained transverse section of the medulla oblongata at the level of the inferior olivary domain. Note that none of the precerebellar nuclei is yet formed; inferior olivary neurons are not yet packed in a club-shaped domain close to the floor plate. $B-D$, Transverse sections were subjected to hybridization and revealed using NBT-BCIP in blue, coupled or not with immunocy tochemistry using an anti-CaBP (anti-calbindin protein) antibody and revealed with DAB. B, At E12, Brn-3.b is expressed by cells located in the submarginal stream (long arrow), whereas no Brn-3.b-expressing cell is observed in the marginal stream (arrowhead). C, Calbindin (brown) is expressed in the hypoglossal nucleus $(X I I)$, in some cells of the vestibular nuclei $(v b)$, and in the ventral part of the subnucleus caudalis of the sensory trigeminal nucleus $(V)$. The domain of expression of netrin-1 (blue) is restricted to epithelial cells forming the floor plate and the ventricular zone $(v z)$, where it discloses a decreasing gradient of expression up to the sulcus limitans (arrows). D, Neogenin is expressed in the whole ventricular zone and in two dorsal bands, which correspond to the rhombic lips (arrow). E, The domain of expression of Unc-5H2 (blue) in the caudal rhombic lip is restricted to the ventricular neuroepithelium dorsal to the sulcus limitans; this distribution is complementary to that of netrin-1. F, The zone of expression of DCC (blue) includes the zone located below the ventricular zone of the caudal rhombic lip, the lower limit of which is indicated by an asterisk; DCC mRNAs are also synthesized in cells leaving the rhombic lips (arrow). Scale bar, $300 \mu \mathrm{m}$.

neurons. Most of these neurons, identified by their CaBP immunoreactivity, express $D C C$ but neither $U n c-5 H 2$ nor $U n c-5 H 3$ mRNA (results not shown).

From E16, IO neurons appear as a laminated structure. IO neurons express $D C C$ in the whole inferior olivary complex from rostral to caudal (Fig. 3A), whereas Unc-5H2 mRNA is only expressed in the lateral pole of the ventral part of the dorsal accessory olive (DAO) (Fig. 3B).
From E17, IO neurons express in a more widespread manner mRNAs for the different members of the two families of netrin-1 receptors: DCC/neogenin, Unc-5H1, Unc-5H2, and Unc-5H3. The analysis of semiserial sections strongly suggests that only some IO neurons co-express $D C C$ and $U n c-5 H 2$ receptor genes (as described below for P0 mice). In addition to the ION, DCC, neogenin, and Unc-5H2 are expressed by neurons of the pontine gray nucleus (another class of precerebellar neurons; data not shown). In the newborn mouse (Fig. 3C,D), when the IO has already acquired its adult cytoarchitecture, $D C C$ mRNA (Fig. 3C) is strongly expressed in the principal olive (PO), in the dorsal cap, the $\beta$-nucleus, and part $\mathrm{c}$ of the caudal medial accessory olive (MAO), whereas expression is low in the DAO. Unc-5H2 (Fig. $3 D)$, Unc-5H3, and neogenin mRNA are expressed in the vertical lamella (VLO) of the caudal MAO and more strongly in the DAO but not in the PO. Thus, only neurons in the caudal MAO express both $D C C$ and $U n c-5 H 2$ mRNA. Moreover, LRN neurons express $D C C$ but not $U n c-5 H 2$. The temporospatial patterns of expression of netrin-1 receptors mRNAs are schematized in Figure 4.

\section{Newborn mice deficient in the expression of netrin-1 lack several compartments of the olivary complex and present olivary ectopias but have a normal cerebellum}

Mutant mice homozygous for a severely hypomorphic allele of netrin-1 were not viable and died within the first $12 \mathrm{hr}$ after birth. The most obvious phenotype in the caudal medulla of the netrin1-deficient mice is the disruption of the IO cytoarchitecture (Figs. $5,6)$. None of the mutant animals studied in Nissl-stained preparations has a normally lamellated IO. In half of the mutants (type II; Fig. 5, right column), the presumptive olivary domain is extremely small and poorly delimited, whereas in the other half (type I; Fig. 5, center column), it is somewhat larger, and some remnants of lamellation are observed, particularly at its rostral aspect. In all mutants, cellular clusters of olivary neurons (see below for their identification) are encountered in the dorsal olivary territory, close to the midline, and ventrally in the vicinity of the pial surface, owing to a great reduction in size of the pyramidal tract. In addition, despite the reduced number of olivary neurons (see below for quantification), the rostrocaudal extent of the IO remnants is rostralized (Fig. 5), because these neurons are frequently observed in the vicinity of the facial nucleus (VII).

The whole IO complex could still be visualized in newborn mice by ISH using Brn-3.b (Fig. 6C,D). In mutant mice, patches of Brn-3.b-positive cells have been detected in the migration stream (Fig. 6D), often asymmetrically distributed. The IO nature of these neuronal clusters (Fig. 6D) was confirmed by complementary information obtained from immunohistochemistry, ISH with DCC antisense probe, and axonal tracing experiments. In control P0 mice, $D C C$ is strongly expressed in the ventral and dorsal lamellae of the PO and in the MAO (Fig. 6E), whereas in mutant mice, $D C C$ mRNA is synthesized by neurons in the ventral half of the medulla oblongata, mainly those apposed to the midline, and occupying a location corresponding to the $\beta$-nuclei in control mice (Fig. $6 F$ ), which are also immunostained with anti-CaBP antibodies (Fig. $6 H$ ). In one case of four examined, DCC mRNA is also ectopically expressed by clusters of cells located more laterally (Fig. 6F). Immunohistochemistry with anti-CaBP and anti-CGRP antibodies was also helpful in identifying IO neurons. In control P0 mice, anti-CaBP immunostains part of the vertical lamella of the MAO comprising the $\beta$-nucleus and the dorsal cap, 


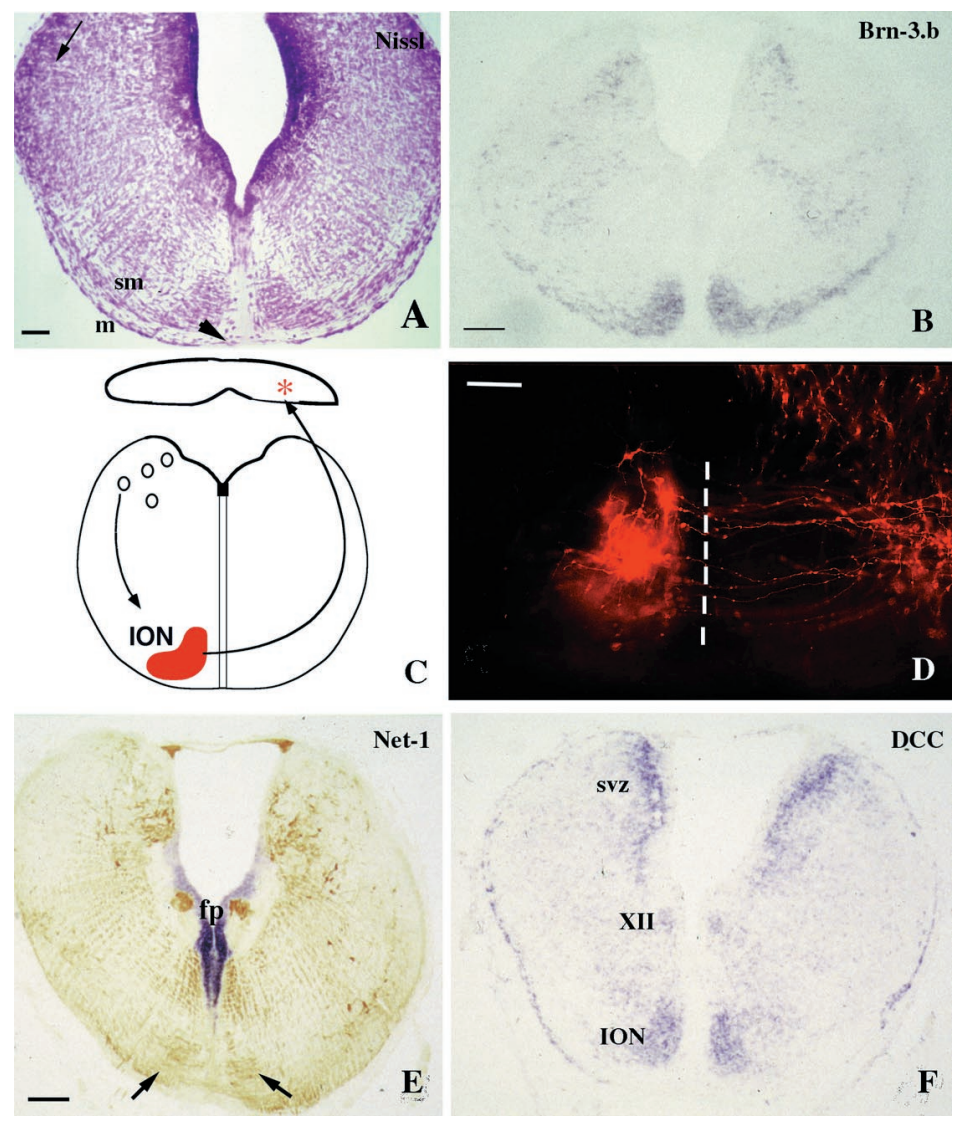

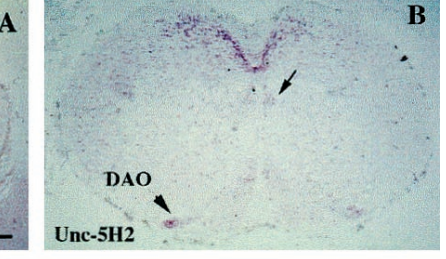

DCC
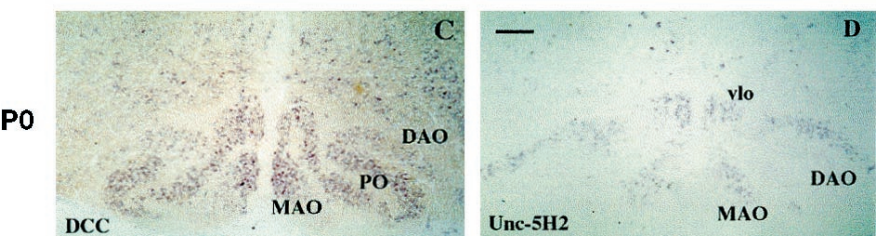

Figure 3. At E16 $(A, B)$, the olive appears as a lamellated structure. All IO compartments express $D C C$ mRNAs $(A)$, whereas $U n c-5 H 2$ mRNAs $(B)$ are only synthesized in the lateral pole of the ventral DAO (arrowhead), as detected after ISH. Motoneurons in the hypoglossal nucleus (thin arrow) express both DCC and Unc-5H2 ( $A, B$, respectively). In newborn mice $(C, D), D C C(C)$ and $U n c-5 H 2(D)$ messengers are expressed differentially in olivary subzones. $D C C$ messengers $(C)$ are expressed in the principal olive $(P O)$ and the medial-accessory olive $(M A O)$, whereas the DAO exhibits a lower level of DCC messengers. Unc-5H2 messengers $(D)$ are expressed in the DAO but not in the PO. Neurons in the vertical lamella (vlo) of the caudal MAO express both Unc-5H2 $(D)$ and $D C C(C)$. Scale bars: $A, B, 500 \mu \mathrm{m} ; C, D, 100 \mu \mathrm{m}$.

the u-shaped (bent) region of the PO, and the ventrolateral enlargement of the DAO (Fig. 6G). In the netrin-1 hypomorphic mice, the vast majority of the neuronal clusters reported above as belonging to $\mathrm{IO}$ neurons are $\mathrm{CaBP}$ immunoreactive (Fig. 6H). Thus, most of the olivary neurons that remain located in the vicinity of the floor plate at birth in netrin-1-deficient newborn mice are CaBP-positive and still express DCC mRNA.

Figure 2. At embryonic day 13, early neurons arriving in the inferior olivary domain express $D C C$ but not $U n c-5 H$ receptors. $A$, Nissl staining allows the visualization of inferior olivary cells compacted close to the floor plate and those migrating in the submarginal stream $(\mathrm{sm})$. In the marginal stream $(\mathrm{m})$, migrating cells are located at the periphery of the section. Some of them are located in the ventral part of the floor plate (arrowhead). B, IO migrating neurons are visualized after ISH with Brn-3.b. $C$, $D$, After a unilateral injection of DiI crystals in the cerebellum, some inferior olivary neurons are retrogradely labeled only contralateral to the injection site with their fibers crossing the midline, demonstrating that their axons have reached the cerebellum, and that the projection is entirely crossed $(D$, dotted line: midline). $E$, Cell bodies of the floor plate $(f p)$ synthesize high levels of netrin-1 mRNAs (blue), with a decreasing gradient dorsally in the germinative zone. CaBP is expressed by part of inferior olivary cell bodies, as revealed by immunocytochemistry (arrows). F, In situ hybridization using a DCC antisense probe. IO neurons (ION) synthesize DCC mRNAs once they have reached the floor plate. The hypoglossal nucleus $(X I I)$ and cells in the subventricular zone $(s v z)$ also synthesize $D C C$. Scale bar, $150 \mu \mathrm{m}$.

As detailed below in the retrograde tracing experiments with DiI, clusters of DiI-labeled neurons occupy medial positions similar to the Nissl-stained clusters of remaining cells, corroborating their inferior olivary nature.

In wild-type mice, several subnuclei in the inferior olivary complex express CGRP: the IO $\beta$-nucleus, the dorsal cap (Fig. $7 A$ ), the dorsal fold of the DAO, and subgroup $\mathrm{c}$ of the MAO (Fig. 7B). In the netrin-1 mutant mice (Fig. 7C,D), CGRPpositive IO neurons are reduced to a medially located, vestigial, ventrodorsal band, apposed to the floor plate; hypoglossal root fiber bundles ran dorsoventrally on both sides of the midline but with a much more acute angle to midline than in normal animals (Fig. 7, compare $A, B$ with $C, D$ ).

We have quantified the total volume occupied by Brn-3.bpositive cells in both "normal" and ectopic locations in mutant mice compared with the volume of Brn-3.b-positive IO cells in control newborn animals. We have established the ratio of remaining cells, both those that are ventromedially located and those that are ectopically located, forming patches of more laterally located cells. The ION volume in P0 control mice is $\sim 0.15 \pm$ $0.005 \mathrm{~mm}^{3}(n=2)$. Taking into account all the netrin-1 mutants examined by ISH with Brn-3.b antisense probe $(n=3)$, the mean of the IO volume (both ectopically and ventrally located) was $0.09 \pm 0.01 \mathrm{~mm}^{3}, \sim 60 \%$ of that of control animals. When quantified independently, ectopic olivary neurons represent $0.05 \pm$ $0.01 \mathrm{~mm}^{3}$; that means that among the remaining $60 \%$ olivary cells in mutant mice, $45 \%$ are located medioventrally, whereas $55 \%$ are distributed ectopically along the migration stream.

It was interesting to note that some IO neurons still succeeded in reaching their final location at the ventral half of the caudal medulla, and we had noticed from ISH using Brn-3.b a hetero- 


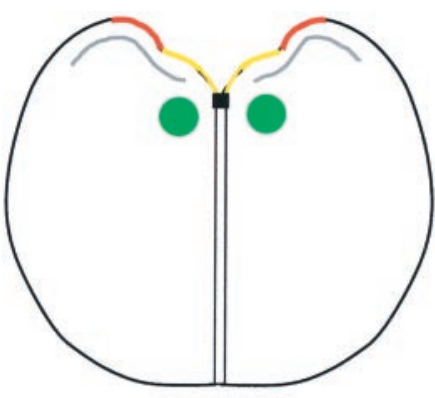

E12

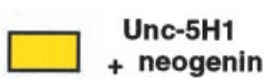

+ neogenin

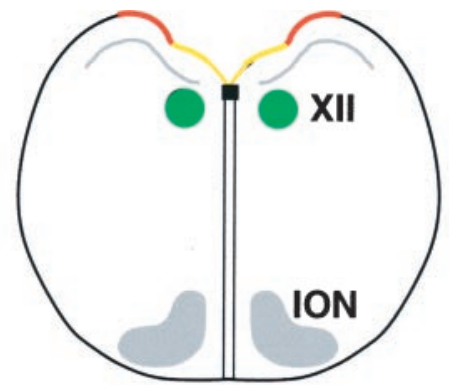

E13
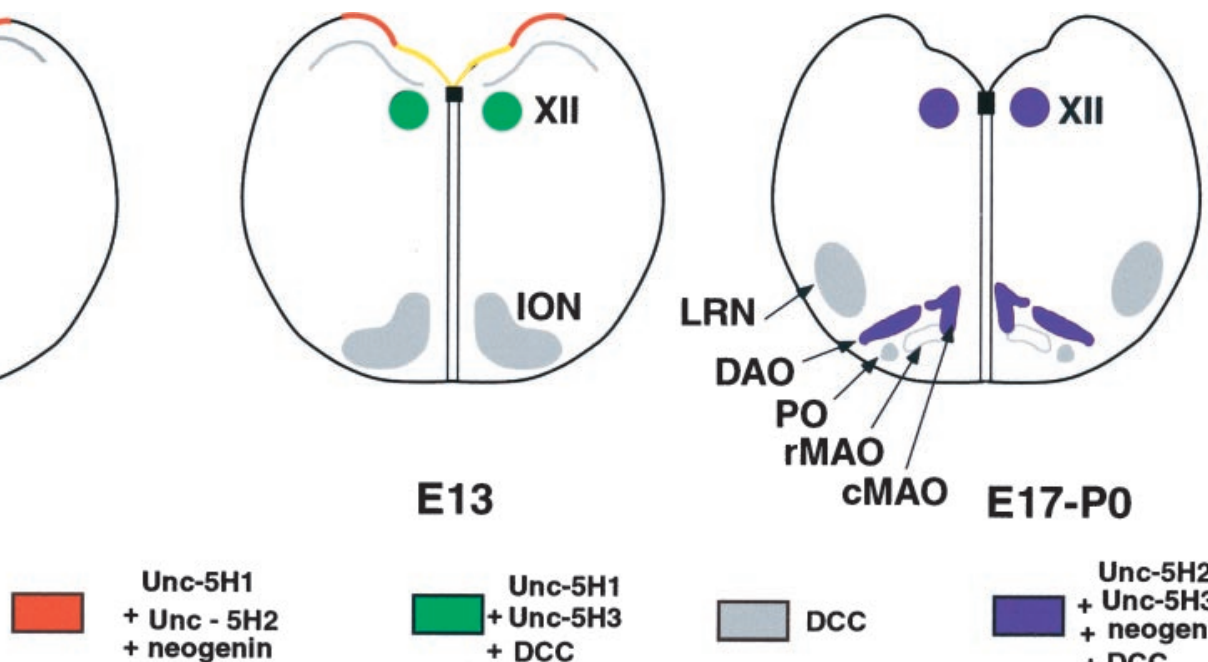

+ Unc - 5H2
+ neogenin
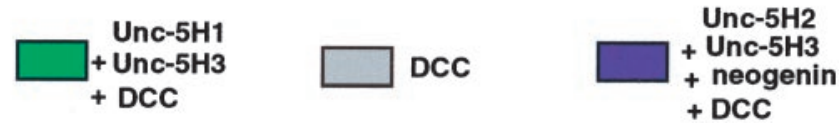

Figure 4. Schematic drawings of the temporospatial changes in expression pattern of netrin-1 receptors Unc-5H1, Unc-5H2, Unc-5H3, DCC, and neogenin in the olivary region at E12, E13, and E17-P0 obtained from ISH.

geneity in their ventromedial organization. To estimate the loss of IO neurons and the volume occupied by remaining neurons in the P0 mutant mice, we performed a volumetric and a cellular densitometric study in both control and netrin-1 mutant mice, using Nissl-stained paraffin sections, and applying the identification criteria detailed in Materials and Methods. These studies corroborated the phenotypic heterogeneity of the mutant mice and revealed two main types of phenotypes in mutants at a 1:1 ratio. In the first phenotype, the ION is extremely atrophic, and only small IO clusters of neurons were identified ventrally; these clusters were dispersed throughout the ventral region of the medulla oblongata, constituting a total volume of $0.015 \mathrm{~mm}^{3}$. In the second phenotype, there is a larger amount of remaining IO neurons, and some areas display a poor but clearly laminated structure, particularly in the rostral regions of the IO complex. The volume occupied by the identified IO in these instances was $\sim 0.027 \mathrm{~mm}^{3}$. Taking into account all the netrin- 1 mutants examined $(n=4)$, the mean of the IO volume was $0.023 \pm 0.004 \mathrm{~mm}^{3}$, only $\sim 23 \%$ of the ION volume in P0 control mice $(0.1 \pm 0.004$ $\left.\mathrm{mm}^{3}\right)$. In the most severely affected mutants, this percentage is smaller, only $\sim 15 \%$ of the control IO volume. The dropout in cellular density is even greater than in volume; thus, although the cellular density of the IO was $11,316 \pm 3399$ cells in control animals, it is only $1605 \pm 283$ cells in the less affected mutant mice and $1339 \pm 220$ cells in the most severely affected ones; that is, ventrally located neurons represent only $\sim 13 \%$ of IO neurons in mutant mice compared with control ones.

\section{Severe defects in location of olivary neurons in netrin- 1 mutants and formation of an abnormal olivocerebellar projection}

At P0, unilateral insertions of DiI crystals in the cerebellum resulted in a massive labeling of the cerebellar plate (Fig. 8). In the precerebellar region of control animals, contralaterally to the site of injection, only the IO neurons were labeled (Fig. $8 A-C$ ). In 11 of 11 cases in control animals, the lateral reticular nucleus was labeled ipsilaterally to the site of injection (Fig. $8 B$ ). All three subcompartments of the LRN were visualized. Decussating olivary axons were observed crossing the midline in a large and organized band, forming an interolivary commissure with mature appearance (Fig. 8C). The density of DiI labeling in the netrin-1 mutant was much lower than in controls. In three of eight mutant mice analyzed, only ipsilateral clusters of IO neurons were retrogradely labeled (Fig. 8D,E). In two of the eight analyzed mutant mice, although most of the labeled IO neurons were located ipsilateral to the injection, a few ventral masses of labeled IO neurons were also located contralaterally in the vicinity of the midline (Fig. $8 D-F$ ). In these mutants, the approximate outline of the IO complex resembled the cytoarchitecture of the least affected mutant mice, as illustrated in Figure 6 from the Nisslstained sections. In the remaining three cases, no clear cellular labeling of IO neurons was obtained either ipsilaterally or contralaterally. Retrograde labeling of patches of IO cells located ectopically dorsolaterally along the migration stream was never observed, suggesting that ectopic neurons, whatever their arrest location, do not project to the cerebellum. Contrary to the normal case, no interolivary commissure was observed, and only a few fibers were wandering in the inferior olivary region (Fig. 8F). These cases could correspond to the most affected cases with cytoarchitectonic criteria in which most IO have disappeared. Thus, the olivocerebellar projection revealed in the mutant mice was, for the most part, abnormal; dorsolaterally ectopic neurons did not project to the cerebellum, whereas most of the ventrally remaining IO neurons projected to the ipsilateral cerebellum to their final ventral location, and only occasional IO neurons projected contralaterally as in control mice.

\section{Both Purkinje cells and the intracerebellar commissure show a normal development in the cerebellum of newborn netrin-1 mutant mice}

At birth, the cerebella of both mutants $(n=8)$ and control mice $(n=11)$ were immature: Purkinje cells form a thick multicellular

correspond to less affected cases, some remnants of olivary lamellation are observed. In type II mutants, small and poorly delimited clusters of IO cells are observed, close to the midline and in the vicinity of the pial surface. Note that in both types, the IO nuclei are rostralized, relative to the location of the facial nuclei. Scale bar, $200 \mu \mathrm{m}$. 

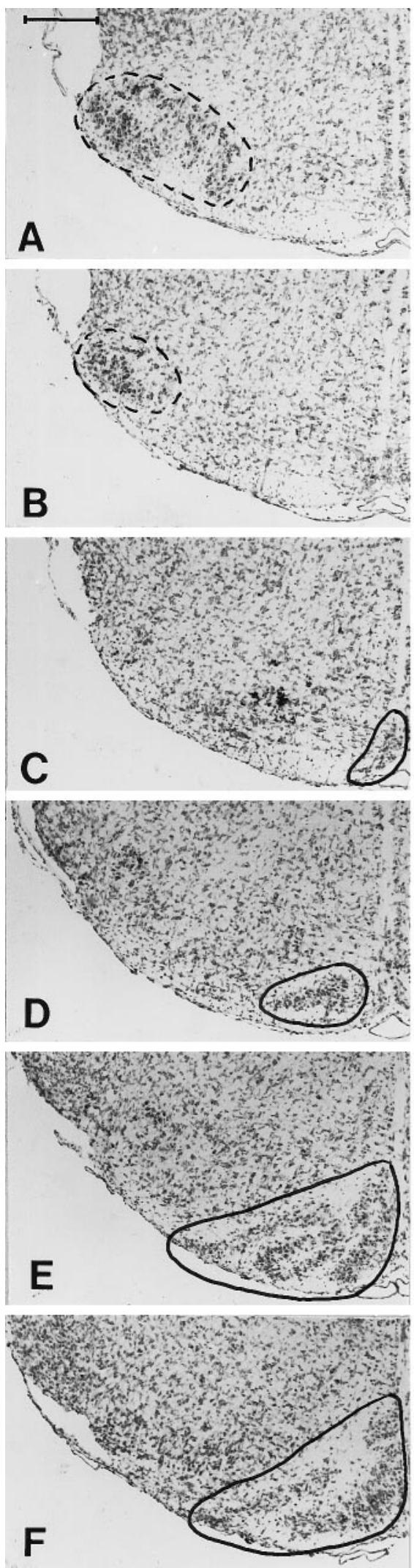
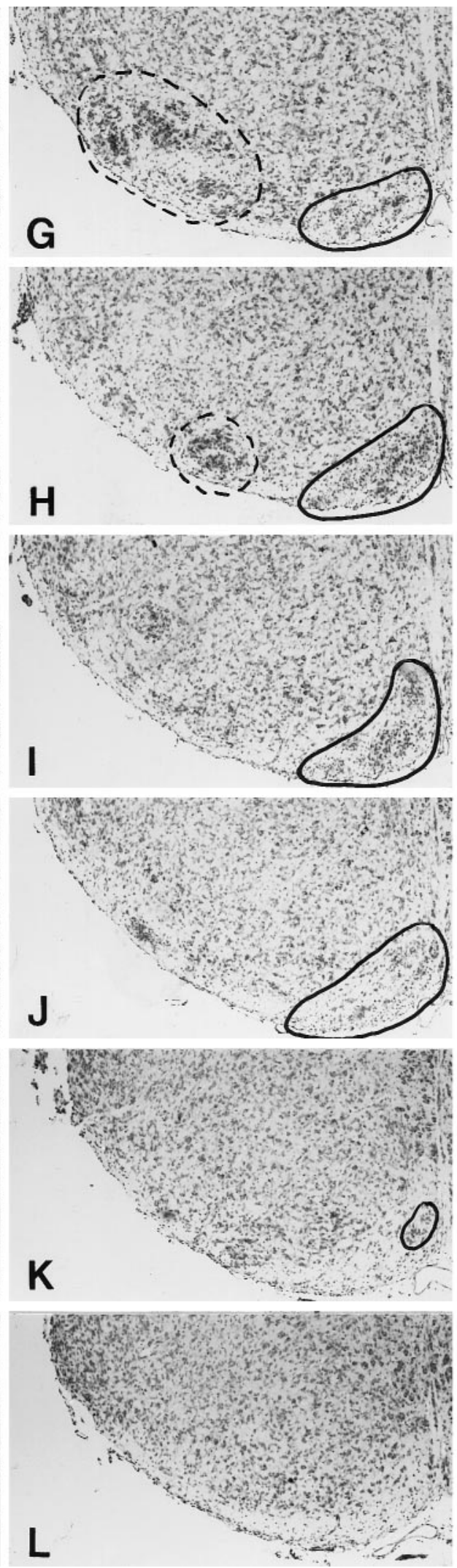

Figure 5. Newborn mice defective in the expression of netrin-1 lack several compartments of the olivary complex (delimited with a solid line): reconstruction of the olivary complex and contiguous fields, from the facial nucleus (VII, delimited with a dashed line) rostrally to the caudal part of the LRN caudally. One of $>24$ sections is illustrated in the control case (left column), whereas 1 of $>6$ sections is illustrated in the two selected mutant mice (center and right columns). Photomicrographs of serial sections, from rostral to caudal, were stained with the Nissl method. Left column, Control animal, with, successively, the facial nucleus $(A, B)$, the principal olive $(\mathrm{PO}, C)$, the MAO, DAO, and PO $(D, E)$, and the caudal MAO and DAO $(F)$. Center and right columns, Two types of mutant mice: mutant of type I (center column) and II (right column). In type I mutants, which (Figure legend continues) 

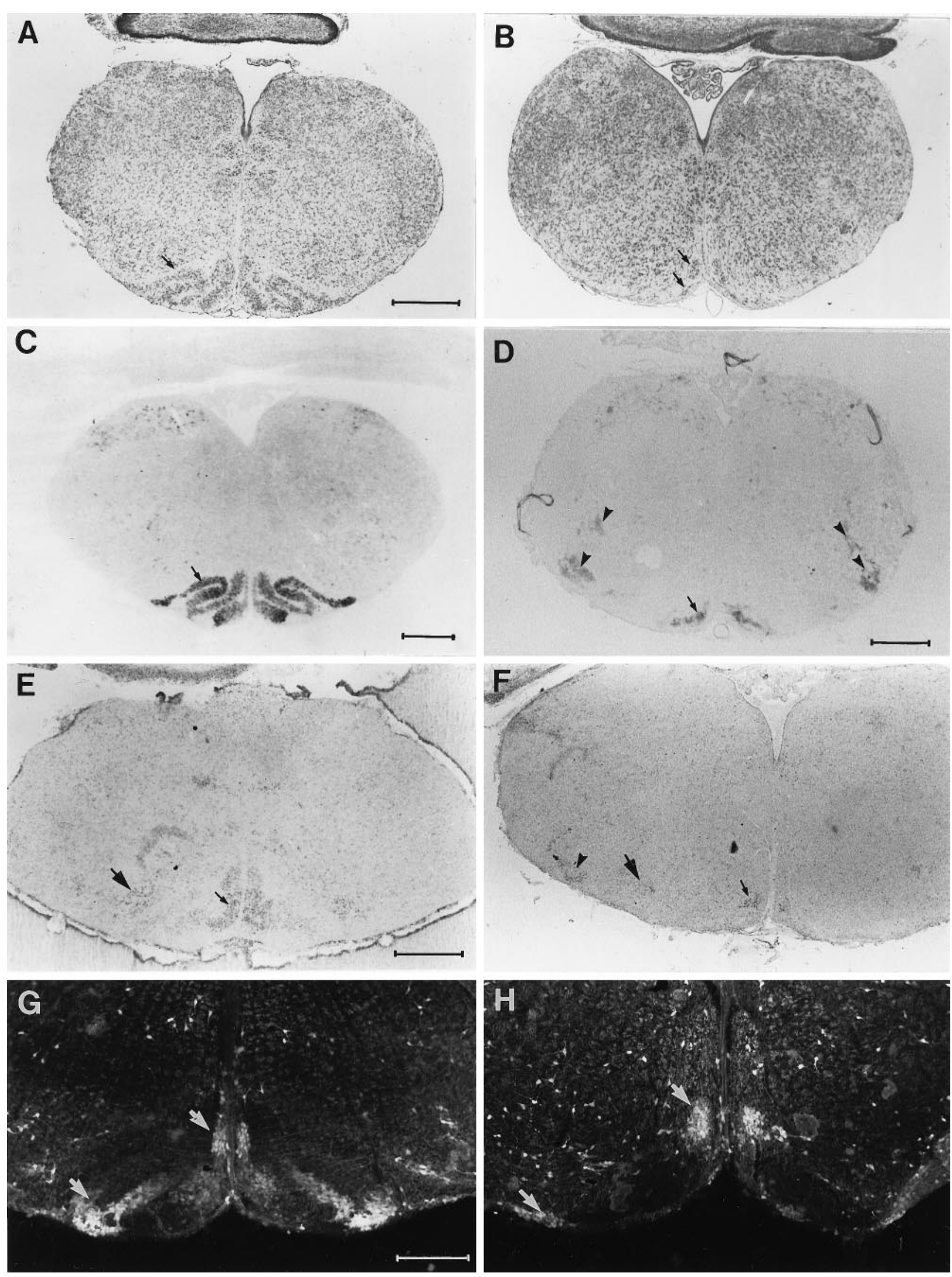

Figure 6. Cytoarchitecture and compartmentalization of the olivary complex in wild-type and netrin-1 mutant newborn mice. Frontal sections of wild-type $(A, C)$ and mutant mice for the expression of netrin-1 $(B, D)$ were stained with the Nissl method $(A, B)$ or by ISH with Brn-3.b (C, $D)$. Only a few IO neuronal masses (small arrows) are maintained ventrally in the mutant $(B, D)$ compared with the well organized (Figure legend continues) 


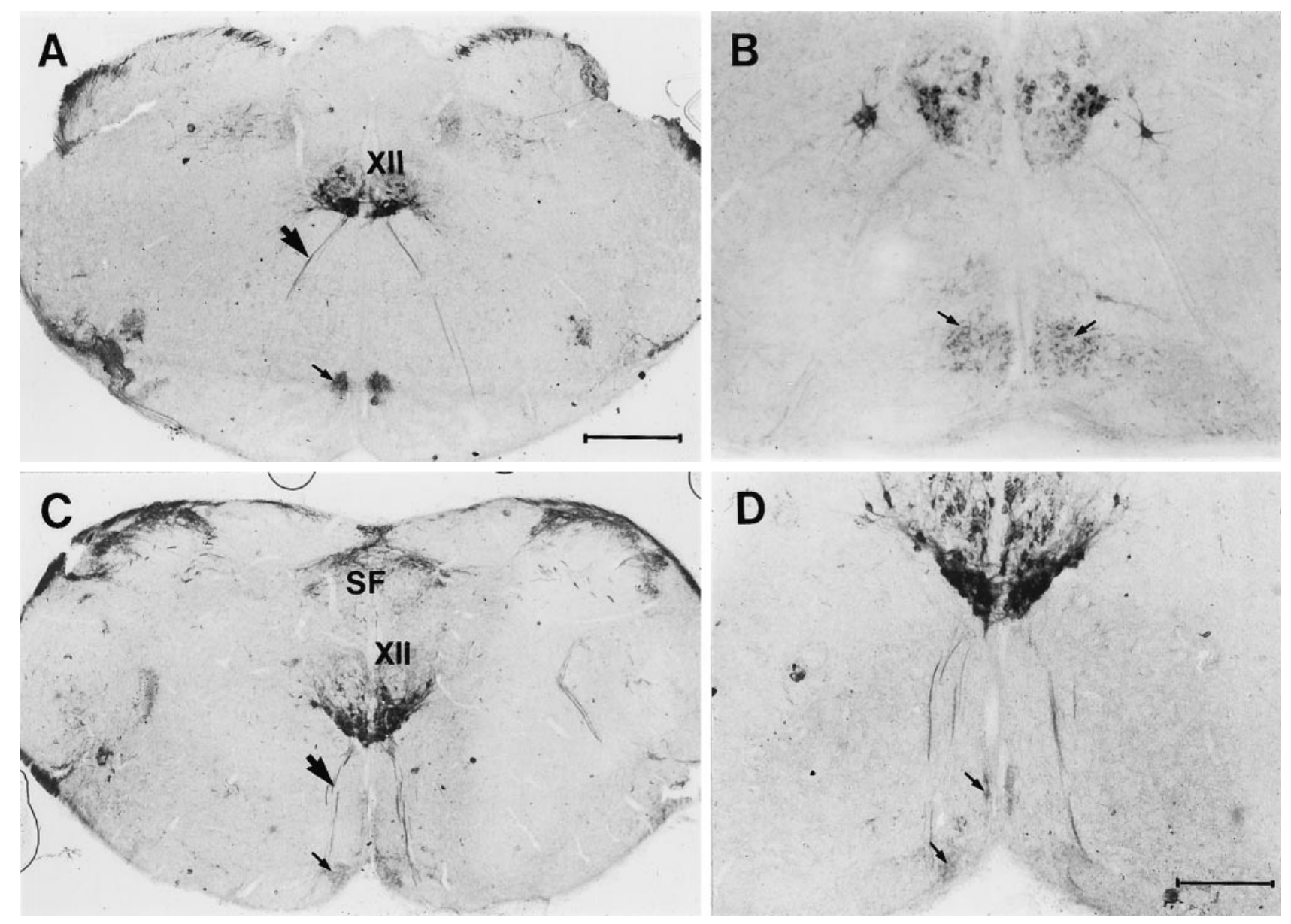

Figure 7. Analysis of CGRP-positive structures in the brainstem of both normal and mutant newborn mice. In the wild-type newborn mice ( $A$, $B$ ), the olivary $\beta$-nucleus expresses CGRP (thin arrows). In the mutant $(C, D)$, a slight immunoreactivity is observed medially; note the marked regression of olivary cell groups. The hypoglossal nucleus $(X I I)$ and its efferent fibers are strongly CGRP-IR in normal and mutant mice $(A, C$, arrows). In the mutant, however, XII root fiber bundles run dorsoventrally on both sides of the midline almost parallel to midline, at variance with normal animals (compare $A, B$ with $C, D)$. In the mutant mice, the commissure of the solitary fascicle $(S F)$ was found at the same rostrocaudal level as the remaining CGRP-positive olivary cells. Scale bar: $A, C, E, F, 400 \mu \mathrm{m} ; B, D, 200 \mu \mathrm{m}$.

layer of CaBP-positive cells [Fig. 9, compare $A$ (normal mice), $B$ (mutant mice)]. It is remarkable that in the netrin-1 mutants, in contrast to the Unc-5h3 mutants (Przyborski et al., 1998), no Purkinje cell ectopias are encountered in the inferior colliculi, at the cerebellar-midbrain border, and the cerebellum is normally foliated. In the cerebellum of the netrin-1 mutant mice, the cerebellar commissure (Fig. $9 C, h b$ ) is observed with the CGRP immunoreactivity, and the decussation of axons of the hook bundle (Fig. 9D, arrow) through the cerebellar midline clearly appears after an injection with DiI in the cerebellar peduncle. Moreover, the external granular layer (EGL) is not affected in mutant mice and covers all cerebellar surface. At birth, DCC protein and mRNA are similarly expressed in postmitotic premigratory granular cells (inner half of the EGL) in normal and mutant mouse cerebella (data not shown).

\section{The floor plate is necessary for the maintenance of the olivary cytoarchitecture}

We have studied the involvement of the floor plate in late migration of IO neurons, when somata stop their translocation inside their axons before crossing the floor plate, ipsilaterally to the rhombic lips they originate from. The study was performed in vitro using slices of brainstem from chick embryos at stage HH28 (equivalent to E5.5), $24 \mathrm{hr}$ after the end of the proliferation of olivary neurons (Armstrong and Clarke, 1979). Within $2 \mathrm{~d}$ in organotypic cultures, olivary neuronal masses have continued their migration but stop at a distance from the floor plate. Indeed, IO masses are never directly apposed to the floor plate and are instead found at a distance of 70-100 $\mu \mathrm{m}$ (Fig. 10A,B). In these explants (E5.5 $+2 \mathrm{~d}$ in vitro $)$, both the migration of olivary masses

$\leftarrow$

structure of the inferior olivary complex ventrally in normal mice $(A, C)$, but ectopic olivary cells (arrowhead) can be visualized after ISH with Brn-3.b ( $D$ ). The whole olivary compartments express DCC, more lightly in the DAO than in other subzones (small arrow) and in the LRN (thick arrow) in the normal newborn mice $(E)$ This expression is maintained in dorsally located remaining olivary cells (small arrow) and in laterally ectopic cells (arrowhead) in mutant animals $(F)$. At the same rostrocaudal levels, CaBP-positive compartments were identified after immunocytochemistry in Texas Red in normal $(G)$ and mutant mice $(H)$. Note that the highest CaBP immunoreactivity is located in both the dorsal cap and the bend of the PO (arrows). In the mutant, high immunoreactivity is maintained in subzones that may correspond to homologous regions (arrows). Scale bar: $A-F, 400 \mu \mathrm{m} ; G, H, 200 \mu \mathrm{m}$. 


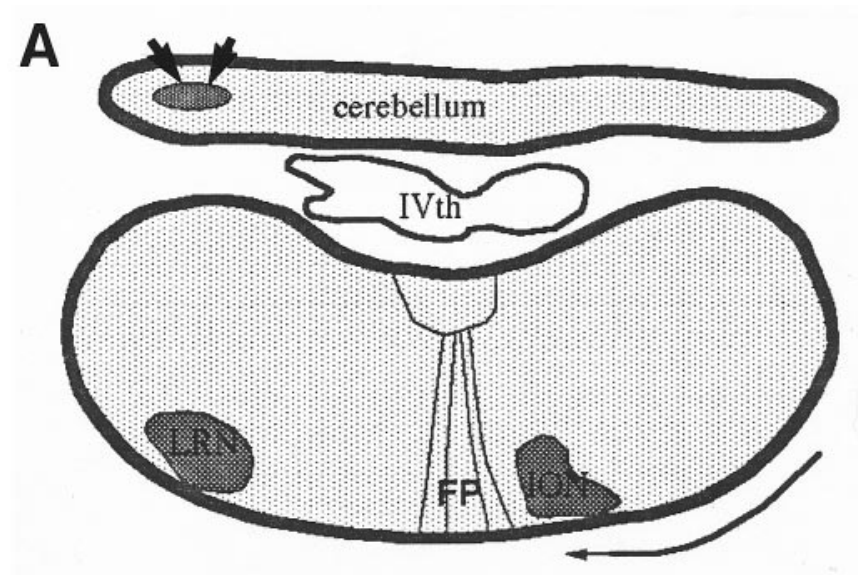

Control animals
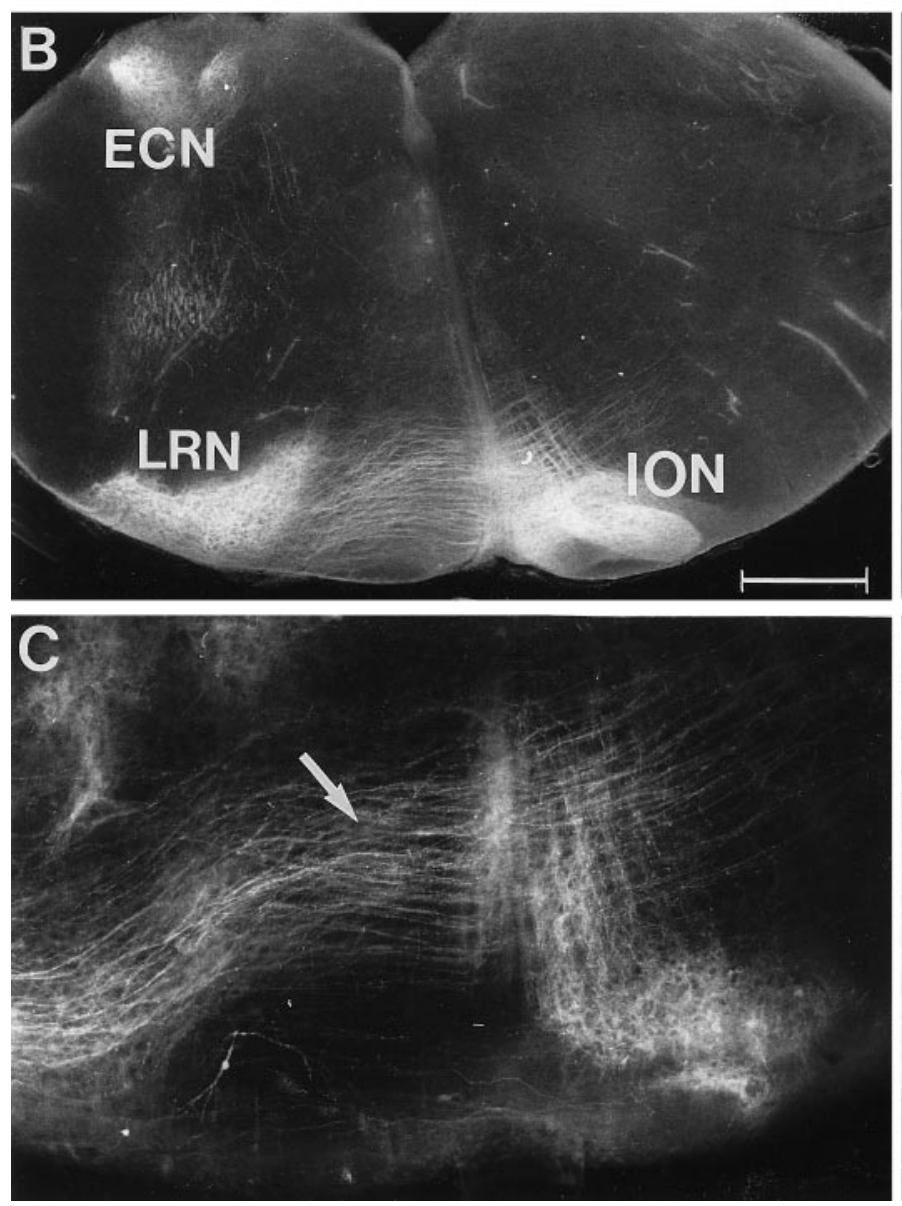

D

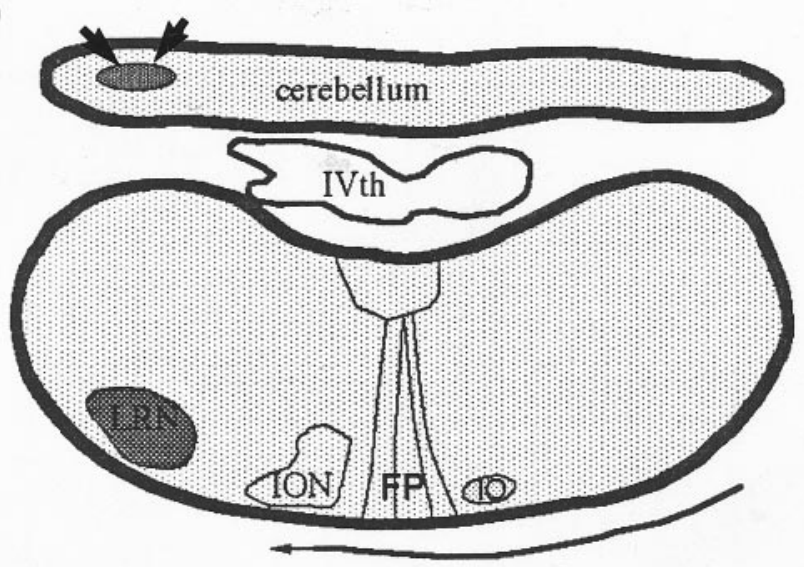

Mutant animals
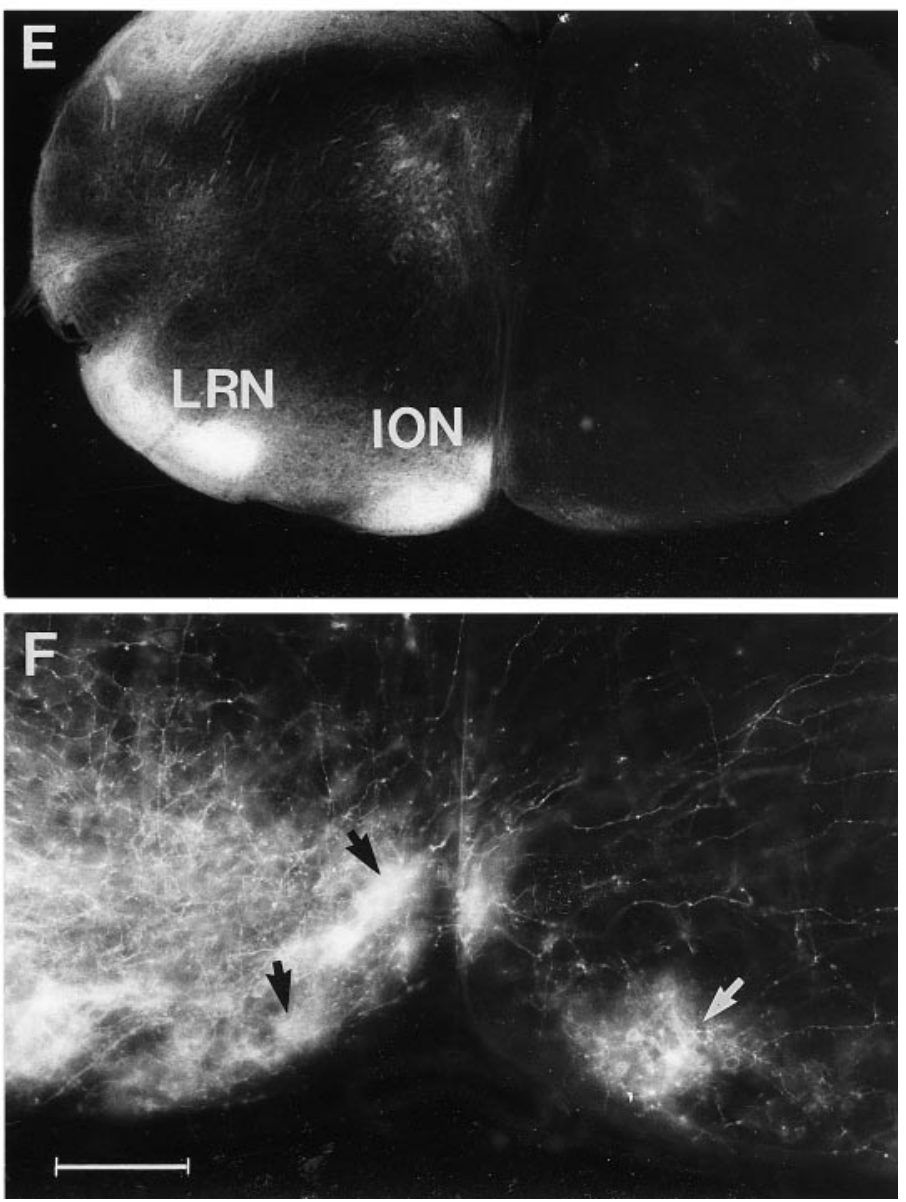

Figure 8. Unilateral DiI injections in the cerebellum and retrograde labeling of precerebellar nuclei in both normal and mutant newborn mice. After the cerebellar injection in normal newborn mice, the inferior olivary complex located contralateral to the injection site and the ipsilateral ECN and LRN are labeled $(A-C)$. Crossing fibers of the olivary commissure are visualized ventrally in the olivary region $(C$, arrow). In mice mutant for the expression of netrin-1, olivary cells are labeled ipsilateral to the injection site. Only a few labeled olivary cells are located contralateral to the injection side $(E, F)$. Scale bars: $B, E, 400 \mu \mathrm{m} ; C, F, 200 \mu \mathrm{m}$.

and their biochemical maturation had occurred (assessed by acquisition of Ben expression; $n=15$ cases corresponding to 30 slices immunopositive for Ben expression, Fig. 10B). Such a maturation corresponded to theoretical E7-E8 in ovo (Fig. 10 $A$; Chédotal et al., 1996) and suggested that the development observed in vitro with slices mimicked that described in ovo, in which IO neurons, their crossing axons, and the floor plate are immu- noreactive using anti-Ben antibody. We considered the ventral location of cellular masses and their Ben expression as the minimal criteria for identifying the ION. We next performed mechanical lesions of the floor plate by removing their cell bodies, which strongly express netrin-1 mRNA (Fig. 10C). This involves removing only the dorsal part of the section without altering the ventral one. The effectiveness of the floor plate lesion was esti- 

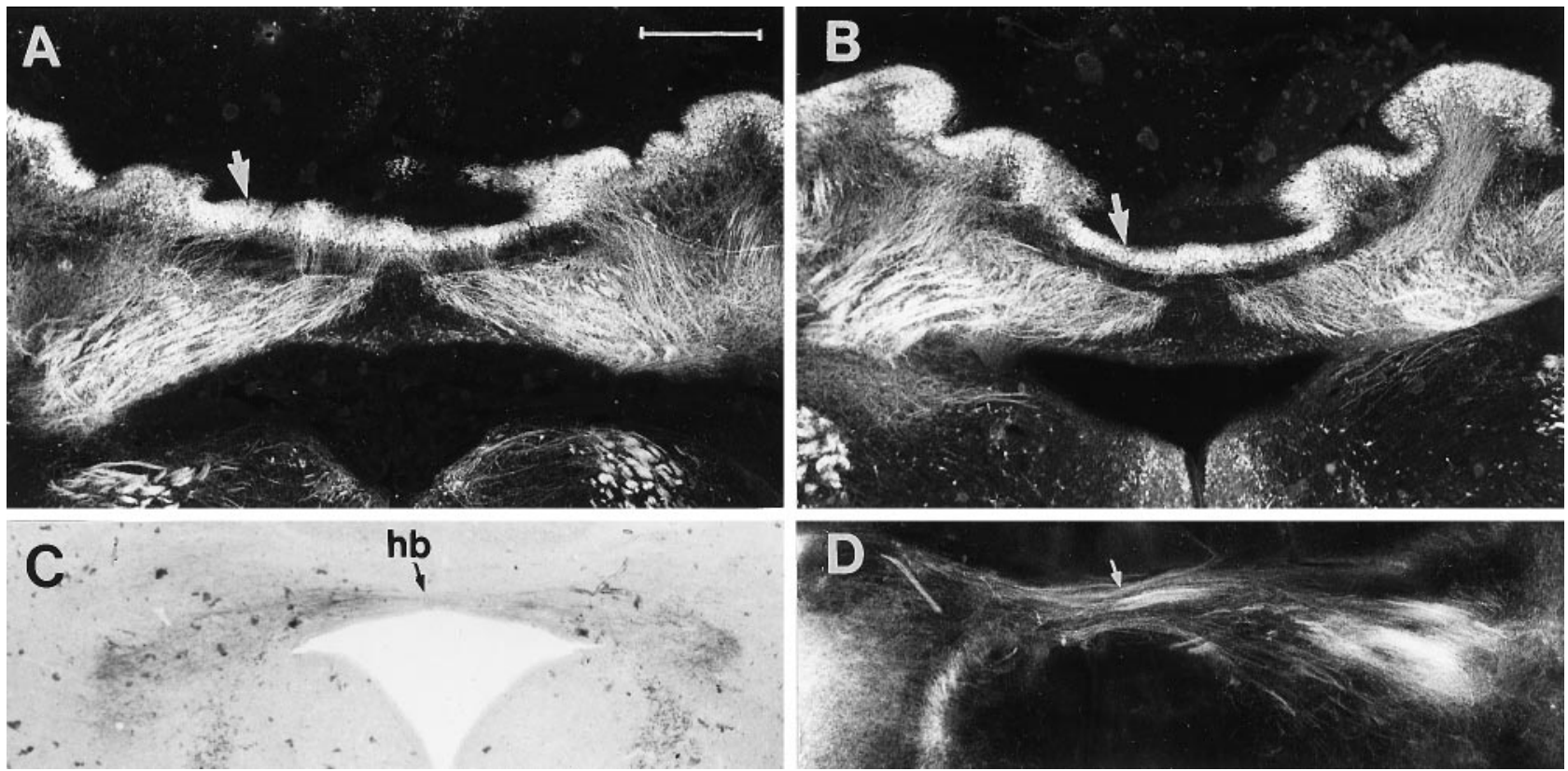

Figure 9. No ectopia can be detected among Purkinje cells in the cerebellum of mutant mice for netrin-1 expression and evidence of the occurrence of the intracerebellar commissure. The domain of expression of $\mathrm{CaBP}$ is the same in normal newborn mice and in mutant mice. The Purkinje cell layer exhibits the same appearance in both normal and mutant mice after immunofluorescence using anti-CaBP (compare $A, B$, respectively; white arrow), and the Purkinje cell axons project in both mice to their proper locations. In the cerebellum of the netrin-1 mutant mice, the cerebellar commissure ( $h b$ ) is observed with the CGRP immunoreactivity $(E)$, and the decussation of axons of the hook bundle (arrow) clearly appears after an injection with DiI in the cerebellar peduncle $(F)$. Scale bar, is $400 \mu \mathrm{m}$.

mated by immunostaining for Ben. When lesioned, the floor plate could be either partially destroyed or totally absent. When partially altered (Fig. 10D), half of the slices presented fused olivary masses, whereas the other half developed normal separated IO masses. When totally absent, 91\% of the olivary Ben-positive neurons were fused on the "ghost" of the floor plate, whereas the IO developed normally in $96 \%$ of control experiments, showing clear Ben immunoreactivity (Fig. 10E).

\section{DISCUSSION}

It has been well established that netrin-1 plays a crucial role in the guidance of certain classes of growing axons. The present study suggests that the involvement of netrin-1 can be extended to the migration and/or survival, of precerebellar nuclei, in particular of ION neurons. We have first studied the expression pattern of netrin-1 and several of its receptors, DCC, neogenin, and Unc-5 family members in the mouse. Some of the receptors are expressed alone or in combination by precursors of IO neurons, and later in their development, more mature IO neurons also express other combinations of netrin receptors. Newborn mutant mice deficient for the expression of netrin-1 have a reduced number of IO cells and the volume of the IO complex is decreased. Moreover, ectopic clusters of IO neurons are visible along the submarginal stream. Remaining olivary structures have a disorganized cytoarchitecture and altered projections; IO axons develop ipsilateral projections instead of projecting to the contralateral cerebellar plate. This aberrant projection could result either from the fact that the cell bodies of IO neurons are ill-positioned in the mutants, having migrated and crossed the midline, or from a lack of crossing of the midline by IO axons. These two alternate hypotheses are discussed.

\section{Involvement of netrin-1 at different stages of 10 development?}

Netrin-1 is expressed in the floor plate for the entire period of IO development, and netrin-1 receptors are expressed by IO neurons. According to the combination of netrin receptors that IO neurons express, netrin- 1 could have a different effect on the IO neurons: attractive, repulsive, or no effect. For instance, in the alar portion of the ventricular zone, IO precursors express Unc5H1, Unc-5H2, and neogenin mRNAs. DCC mRNA is expressed by postmitotic cells located below the ventricular zone. The activation of Unc-5H1 and 2 and neogenin receptors (a DCCrelated protein) by netrin-1 could play a repulsive role in the early migration of IO precursors from the rhombic lips and help initiate the early circumferential trajectory of these neurons. At a later stage, when IO neurons are compacted close to the midline, they express DCC but none of the Unc-5H receptors. Expression of DCC alone has not so far been reported to lead to a repulsive response to netrins. The expression of DCC alone is thus not sufficient to explain why IO cell bodies remain at a distance from the midline; however, it remains possible that other molecules, perhaps other undescribed UNC5 homologs, could be coexpressed with DCC at the IO cell surface (Kidd et al., 1998; Stoeckli, 1997). Finally, at later stages of maturation, when IO neurons begin to be organized in a lamellated structure, they express a variety of netrin-1 receptors with a pattern that suggests a possible role of netrin- 1 in the development of the topographic projections. Indeed, Unc-5H and DCC family members are expressed in some IO subzones, coincident with the acquisition of the lamellated aspect of the olive and with the entrance of axons in the cerebellum. The step of lamellation involves movements of cells that were previously packed close to the floor plate. These movements probably require repulsive mechanisms, which allow 

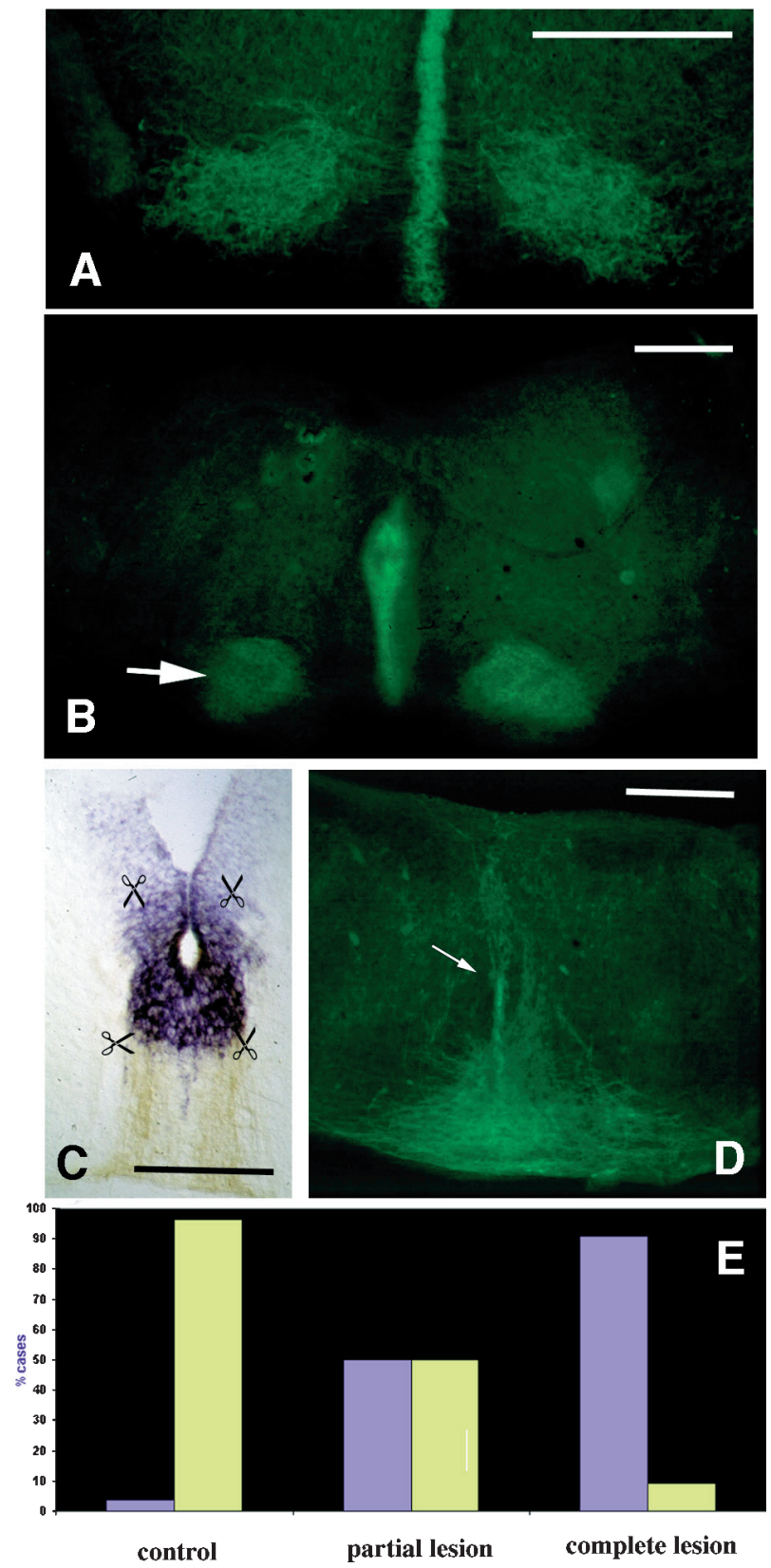

fused IO

separated IO

Figure 10. Migration of inferior olivary cells and biochemical maturation occur in vitro. $A$, Transverse sections of an E8 chick embryo stained for immunocytochemistry with anti-Ben antiserum revealed with FITC (green). The floor plate and the inferior olives express Ben; crossing fibers are visualized through the floor plate $(A)$. $B$, Slice of a chick embryo at day 5.5 (HH28) after $2 \mathrm{~d}$ in culture and stained for immunocytochemistry using Ben revealed with FITC ( green). IO masses reach their appropriate locations at both sides of the floor plate (arrow). Netrin-1 mRNAs are strongly expressed in the cell bodies of the floor plate in chick $\mathrm{HH} 28-\mathrm{HH} 29$, as revealed by $\mathrm{ISH}$, and the fibers of the floor plate express $\mathrm{CaBP}$ protein, revealed with DAB by immunocytochemistry $(C)$. After a mechanical lesion of the epithelial cells of the floor plate, fibers of the floor plate degenerate more or less totally, and olivary masses are fused on the ghost midline (arrow). D, According to the completeness of the lesion, fibers degenerate partially $(D)$ or totally. In control cases, $98 \%$ of the olivary masses are located on each side of the midline; when the floor plate is partially lesioned, half of the slices exhibit separated ( yellow) olivary masses, whereas in the other half, they are fused ( purple). In cases with no more floor plate, olivary masses are fused in $90 \%$ cases $(E)$. Scale bars: $A, B, D, 200 \mu \mathrm{m} ; C, 100 \mu \mathrm{m}$. cells to move away from the midline (Bourrat and Sotelo, 1991). It is remarkable that the Unc-5H2 gene is expressed in the lateral and rostral DAO, a IO subzone that projects specifically to band $\mathrm{c}$ in the cerebellum. Further investigations using antibodies against Unc-5 homologs will allow the visualization of these proteins and the projection pattern of climbing fibers in comparison with DCC proteins to study their possible roles in the development of topographic maps in the cerebellum.

\section{Reduction in number of inferior olivary neurons in the netrin-1 homozygous mutant mice}

Phenotypic analysis of netrin-1-deficient mice has previously revealed the hypoplasia of the optic nerve and the absence of corpus callosum and pontine nuclei (Serafini et al., 1996; Deiner et al., 1997). We now report the dramatic effect of netrin-1 mutation on the development of the IO complex, with a loss of $40 \%$ of the total cellular volume in this structure. In netrin-1 mutant mice, cerebellar development seems to be normal until P0, whereas the number of IO neurons is reduced, strengthening the hypothesis of an involvement of netrin-1 and the floor plate in the survival of these neurons early in development, before any contacts with their cerebellar targets are established. This could result either from a reduced number of IO neurons that are generated or more probably from a loss of IO postmitotic neurons during their migration from the rhombic lips toward the ventral midline. We found that netrin-1 and its receptors neogenin and Unc-5H1 and 2 are expressed in the rhombic lips. It could thus be hypothesized that netrin would be involved in the initial sorting out of IO neurons from the ventricular zone. In favor of this hypothesis, it has been reported in chick embryos that a failure of migration of neuroblasts from the ventricular zone into the optic tectal plate (induced by antisense integrin) resulted in a decreased number of neurons at their final destination (Galileo et al., 1992). Further experiments will be necessary to assert whether netrin-1 directly affects IO neuronal survival or whether the cell death is a consequence of the absence of migration. Recent data have been reported from culture experiments, concerning the possible involvement of the DCC gene product in apoptosis (Mehlen et al., 1998). DCC would induce apoptosis in the absence of ligand binding but would block apoptosis when engaged by netrin-1. In mutant mice for netrin-1 expression, the rate of cell death could be increased if DCC receptors were still expressed during the IO development in the absence of their ligand. It would be interesting to compare the phenotype of DCC knock-out mice with the one reported here for netrin-1 mutant mice. Further investigations using in toto ISH with Brn-3.b on the brainstem of both normal and mutant embryos will be useful to determine the timing of the loss of IO neurons.

\section{Ectopic IO cells located along the migratory stream are viable at $\mathrm{PO}$, but their biochemical maturation seems to be affected}

Olivary ectopia, corresponding to $\sim 50 \%$ of the remaining cells in newborn mice, have been observed along the migratory pathway, most often located dorsal to the LRN. Such a result confirms the involvement of netrin- 1 in the migration of IO cells. Ectopic IO cells would correspond to neurons whose cell bodies are not attracted enough to the midline or not repulsed enough from the ventricular zone; they presumably stop along the migration pathway in an asymmetric way in the absence of specific signal directing migration. It is interesting to note that these ectopic IO cells could only be easily detected by ISH using Brn-3.b or in rare cases DCC, because none of these ectopic cells expressed $\mathrm{CaBP}$ or 
CGRP. This observation suggests that ectopic neurons are specifically cells that would have belonged to a CGRP- and CaBPnegative subzone of the IO. Indeed, CaBP-positive IO cell clusters are present in mutant mice but are only located ventromedially. This would suggest that cells of different subzones of the ION have a different susceptibility to netrin-1. Another possibility would be that $\mathrm{CaBP}$ expression is regulated as a function of the environment and starts to be expressed once IO cells are located in the proper region in the vicinity of the floor plate or when their axons have reached the cerebellum and develop their cerebellar projection.

\section{The aberrant ipsilateral olivary projection in mutant mice likely reflects either the absence of an attractive effect of netrin-1 on 10 axons or an absence of stop signal for IO neurons before they cross the midline}

Two hypotheses may account for the development of the ipsilateral projection of IO cells to the cerebellum. The first is based on the assumption that lack of netrin-1 would prevent the IO axon from being attracted to the floor plate. In this case, the cell body would reach the vicinity of the floor plate, but its axon would remain ipsilateral and would contact the closer cerebellar plate, that is to say ipsilaterally. Such a hypothesis implies that some IO cell bodies can migrate toward the floor plate, without translocating through their axon, which, together with the observed lack of cerebellar projections originated from ectopic IO neurons, argue against this explanation. In addition, E3.5-E5 chick caudal rhombic lip explants were cultured in a collagen gel matrix, facing COS cells transfected with a netrin-1 expression plasmid (our unpublished results). In these confrontational assays, netrin-1 affects neither axon outgrowth nor growth direction, suggesting that netrin-1 is not implied in attracting olivary axons.

A second hypothesis would rely on an abnormal midline crossing of olivary cell bodies. In rodents, Bourrat and Sotelo (1988) have shown that IO neurons were arrested before crossing the floor plate, and some authors have reported a scant transient ipsilateral projection (Sherrard and Bower, 1986). The fact that some IO neurons are able to migrate contralaterally in rat has been proposed by Lopez-Roman and Armengol (1994). In the present study, from DiI retrograde tracing in normal mice, no ipsilateral IO population could be visualized, suggesting that such an IO-crossing event remains a minor one in normal mice. After in vitro lesions of the floor plate, masses of somata of olivary neurons are no longer arrested at a distance from the midline but instead fuse at the midline. In netrin-1-deficient mice, the ratio of contralaterally versus ipsilaterally projecting olivary neurons is completely reversed compared with controls: IO neurons are positioned ipsilaterally instead of contralaterally to their cerebellar projection. In contrast, the floor plate crossing occurs differently for LRN and inferior olivary neurons. In netrin-1 mutant mice, the LRN remains located caudally, and their somata have normally crossed the floor plate. Correlated with this, it appears that LRN cells do not express Unc-5H2 mRNA in normal mice. This observation suggests that the expression of UNC5H2 might be causally involved in directing the choice of marginal and submarginal migration paths.

\section{Some IO axons reach the cerebellum in the absence of netrin-1}

In experiments involving retrograde tracing in the cerebellum, $63 \%$ of the mutants display a labeling of medially located IO neurons, whereas in the other $37 \%$, no labeling could be detected. These observations show that some olivary neurons are still able to project to the cerebellum in mutant mice, despite their ipsilateral location. Thus, in the longitudinal outgrowth of the axons to the cerebellum, netrin-1 does not appear as a key element. However, as discussed above, we cannot definitely exclude a possible involvement of netrin-1 in the axonal guidance through the floor plate. If IO axons manage to cross the midline in the absence of netrin-1, contact-dependent guidance molecules such as axonin 1 or neuron-glia cell adhesion molecule-related cell adhesion molecule could allow axonal crossing of the floor plate, as demonstrated in the case of commissural axons (Stoeckli and Landmesser, 1995; Stoeckli et al., 1997). Netrin-1 could be important for attracting olivary cell bodies but not their axons, as suggested by the different behaviors of cell bodies and axons when crossing the floor plate. Thus, although neuronal migration is dependent on netrin-1, IO axons (climbing fibers) could possibly cross the midline and enter the cerebellum through a contact-dependent phenomenon directed by molecules of the superfamily of immunoglobulins or other molecules involved in axon guidance (Stoeckli, 1997; Kidd et al., 1998).

\section{Mutant mice present some variability in the degree of development of the remaining 10 complex: a threshold phenomenon?}

With regard to the morphology of the IO complex, netrin-1 mutant mice can be divided in two main types, one with only a few diff use olivary clusters, the other with a reduced IO complex and a poor lamellation. This could result from either a variable penetrance of the mutation or by the way the mutation was obtained: a gene trap in the netrin-1 gene, which could, at least in principle, lead to variable amounts of splicing and netrin-1 restoration (see Serafini et al., 1996). A precedent for partial penetrance of a netrin-1 mutant phenotype has been documented for the hypoplasia of the optic nerve, which varied from a mild reduction to an almost complete loss of the nerve and which is similar to that observed in null mutants for DCC, in which there is no possibility of restoration of DCC function (Deiner et al., 1997). The phenotypic diversity in ION concerns both the degree of development of the IO cytoarchitecture and the cellular volume and density. It is interesting to note that the most lamellated structures are observed when the rate of cell survival is the highest. If more cells succeed in leaving the rhombic lips and arrive to the floor plate, they may reach a critical mass in which the cells can go through cell-to-cell interactions leading to a rudimentary lamellation. This hypothetical explanation of the floor plate action also provides an explanation for the results reported here with chick embryos: when the in vitro lesions of the floor plate are total, or in half of the partial lesions, both IO masses are fused. In the other half cases of partial lesions, presumably when the extent of the floor plate does not allow the inferior threshold to be reached, IO masses are maintained at distance from each other.

\section{REFERENCES}

Ackerman SL, Kozak LP, Przyborski SA, Rund LA, Boyer BB, Knowles, BB (1997) The mouse rostral cerebellar malformation gene encodes an UNC-5-like protein. Nature 386:838-842.

Altman J, Bayer SA (1980) Development of the brain stem in the rat. I. Thymidine-radiographic study of the time of origin of neurons of the lower medulla. J Comp Neurol 194:1-35.

Altman J, Bayer SA (1987a) Development of the precerebellar nuclei in the rat: II. The intramural olivary migratory stream and the neurogenetic organization of the inferior olive. J Comp Neurol 257:490-512.

Altman J, Bayer SA (1987b) Development of the precerebellar nuclei in the rat: IV. The anterior precerebellar extramural migratory stream 
and the nucleus reticularis tegmenti pontis and the basal pontine gray. J Comp Neurol 257:529-552.

Armstrong RC, Clarke PGH (1979) Neuronal death and the development of the pontine nuclei and inferior olive in the chick. Neuroscience 4:1635-1647.

Bourrat F, Sotelo C (1988) Migratory pathways and neuritic differentiation of inferior olivary neurons in the rat embryo. Axonal tracing study using the in vitro slab technique. Brain Res 467:19-37.

Bourrat F, Sotelo C (1991) Relationships between neuronal birthdates and cytoarchitecture in the rat inferior olivary complex. J Comp Neurol 313:509-521.

Chédotal A, Pourquié O, Ezan F, San Clemente H, Sotelo C (1996) BEN as a presumptive target recognition molecule during the development of the olivocerebellar system. J Neurosci 16:3296-3310.

Coggeshall RE, Lekan HA (1996) Methods for determining numbers of cells and synapses: a case for more uniform standards of review. J Comp Neurol 364:6-15.

Culotti JG, Kolodkin AL (1996) Function of netrins and semaphorins in axon guidance. Curr Opin Neurobiol 6:81-88.

Deiner MS, Kennedy TE, Fazeli A, Serafini T, Tessier-Lavigne M, Sretavan DW (1997) Netrin-1 and DCC mediate axon guidance locally at the optic disc: loss of function leads to optic nerve hypoplasia. Neuron 19:575-589.

Fazeli A, Dickinson SL, Hermiston ML, Tighe RV, Steen RG, Small CG, Stoeckli ET, Keino-Masu K, Masu M, Rayburn H, Simons J, Bronson RT, Gordon JI, Tessier-Lavigne M, Weinberg RA (1997) Phenotype of mice lacking functional deleted in colorectal cancer (Dcc) gene. Nature 386:796-804.

Galileo DS, Majors J, Horwitz AF, Sanes JR (1992) Retrovirally introduced antisense integrin RNA inhibits neuroblast migration in vivo. Neuron 9:1117-1131.

Hamburger V, Hamilton HL (1951) A series of normal stages in the development of the chick embryo. J Morphol 88:49-92.

Hong K, Leonardo ED, Tessier-Lavigne M, Poo M, Hinck L (1998) In: Cold Spring Harbor meeting: axon guidance and neural plasticity, $\mathrm{p} 85$. Cold Spring Harbor, NY: Cold Spring Harbor Laboratory.

Keino-Masu K, Masu M, Hinck L, Leonardo ED, Chan SS, Culotti JG, Tessier-Lavigne M (1996) Deleted in colorectal cancer (DCC) encodes a netrin receptor. Cell 87:175-185.

Kennedy TE, Serafini T, de la Torre JR, Tessier-Lavigne M (1994) Netrins are diff usible chemotropic factors for commissural axons in the embryonic spinal cord. Cell 78:425-435.

Kidd T, Brose K, Mitchell KJ, Fetter RD, Tessier-Lavigne M, Goodman CS, Tear G (1998) Roundabout controls axon crossing of the CNS midline and defines a novel subfamily of evolutionarily conserved guidance receptors. Cell 92:205-215.

Kingsbury BF (1920) The extent of the floor-plate of His and its significance. J Comp Neurol 32:113-135.

Leonardo ED, Hinck L, Masu M, Keino-Masu K, Ackerman SL, TessierLavigne M (1997) Vertebrate homologues of C. elegans UNC-5 are candidate netrin receptors. Nature 386:833-838.

Livesey FJ, Hunt SP (1997) Netrin and netrin receptor expression in the embryonic mammalian nervous system suggests roles in retinal, striatal, nigral, and cerebellar development. Mol Cell Neurosci 8:417-429.

Lopez-Roman A, Armengol JA (1994) Morphological evidence for the presence of ipsilateral inferior olivary neurons during postnatal devel- opment of the olivocerebellar projection in the rat. J Comp Neurol 350:485-496.

Mehlen C, Rabizadeh S, Snipas SJ, Assa-Munt N, Salmvesen GS Bredesen DE (1998) The DCC gene product induces apoptosis by a mechanism requiring receptor proteolysis. Nature 395:801-804.

Métin C, Deleglise D, Serafini T, Kennedy TE, Tessier-Lavigne M (1997) A role for netrin-1 in the guidance of cortical efferents. Development 124:5063-5074.

Myat A, Henrique D, Ish-Horowicz D, Lewis J (1996) A chick homologue of Serrate and its relationship with Notch and Delta homologues during central neurogenesis. Dev Biol 174:233-247.

Pini A (1993) Chemorepulsion of axons in the developing mammalian central nervous system. Science 261:95-98.

Pourquié O, Coltey M, Thomas J-L, Le Douarin NM (1990) A widely distributed antigen developmentally regulated in the nervous system. Development 109:743-752.

Przyborski SA, Knowles BB, Ackerman SL (1998) Embryonic phenotype of Unc5h3 mutant mice suggests chemorepulsion during the formation of the rostral cerebellar boundary. Development 125:41-50.

Rakic P (1990) Principles of neural cell migration. Experientia 46:882-891.

Ramon y Cajal S (1892) La rétine des vertébrés. La Cellule 9:121-255.

Richards LJ, Koester SE, Tuttle R, O'Leary DDM (1997) Directed growth of early cortical axons is influenced by a chemoattractant released from an intermediate target. J Neurosci 17:2445-2458.

Serafini T, Kennedy A, Galko MJ, Mirzayan C, Jessel TM, TessierLavigne M (1994) The netrins define a family of axon outgrowthpromoting proteins homologous to C. elegans UNC-6. Cell 78:409-424.

Serafini T, Colamarino SA, Leonardo ED, Wang H, Beddington R, Skarnes WC, Tessier-Lavigne M (1996) Netrin-1 is required for commissural axon guidance in the developing vertebrate nervous system. Cell 87:1001-1014.

Sherrard RM, Bower AJ (1986) An ipsilateral olivocerebellar connection: an autoradiographic study in the unilaterally pedunculotomised neonatal rat. Exp Brain Res 61:355-363.

Stoeckli ET (1997) Molecular mechanisms of growth cone guidance: stop and go? Cell Tissue Res 290:441-449.

Stoeckli ET, Landmesser LT (1995) Axonin-1, Nr-CAM, and Ng-CAM play different roles in the in vivo guidance of chick commissural neurons. Neuron 14:1165-1179.

Stoeckli ET, Sonderegger P, Pollerberg GE, Landmesser LT (1997) Interference with axonin-1 and NrCAM interactions unmasks a floor-plate activity inhibitory for commissural axons. Neuron 18:209-221.

Stoppini L, Buchs P-A, Muller D (1991) A simple method for organotypic cultures of nervous tissue. J Neurosci Methods 37:173-182.

Tessier-Lavigne M, Placzek M, Lumsden AG, Dodd J, Jessell TM (1988) Chemotropic guidance of developing axons in the mammalian central nervous system. Nature 336:775-778.

Wassef M, Chédotal A, Cholley B, Thomasset M, Heizmann CW, Sotelo C (1992) Development of the olivocerebellar projection in the rat: I. Transient biochemical compartmentation of the inferior olive. J Comp Neurol 323:519-536.

Wyatt S, Ensor L, Begbie J, Reichardt LF, Latchman DS (1998) NT-3 regulates expression of Brn-3a but not Brn-3b in developing mouse trigeminal sensory neurons. Mol Brain Res 55:254-264. 